\title{
Inorganic mercury accumulation in brain following waterborne exposure elicits a deficit on the number of brain cells and impairs swimming behavior in fish (white seabream-Diplodus sargus)
}

\author{
Patrícia Pereira $^{\mathrm{a}, *, 1}$, Sónia Puga ${ }^{\mathrm{b}, \mathrm{c}, 1}$, Vera Cardoso ${ }^{\mathrm{b}, \mathrm{c}}$, Filipa Pinto-Ribeiro ${ }^{\mathrm{b}, \mathrm{c}}$, \\ Joana Raimundo $^{\mathrm{d}}$, Marisa Barata ${ }^{\mathrm{e}}$, Pedro Pousão-Ferreira ${ }^{\mathrm{e}}$, Mário Pacheco ${ }^{\mathrm{a}, 2}$, \\ Armando Almeida ${ }^{\mathrm{b}, \mathrm{c}, 2}$ \\ a Department of Biology and CESAM, University of Aveiro, 3810-193 Aveiro, Portugal \\ ${ }^{\mathrm{b}}$ Life and Health Sciences Research Institute (ICVS), School of Health Sciences (ECS), Campus of Gualtar, University of Minho, 4750-057 Braga, Portugal \\ ' ICVS/3B's-PT Government Associate Laboratory, Braga/Guimarães, Portugal \\ d IPMA-Portuguese Institute for the Sea and Atmosphere, Av. Brasília, 1449-006 Lisbon, Portugal \\ e IPMA-Aquaculture Research Station, 8700-005 Olhão, Portugal
}

\section{A R T I C L E I N F O}

\section{Article history:}

Received 16 July 2015

Received in revised form

30 November 2015

Accepted 30 November 2015

Available online 2 December 2015

\section{Keywords:}

Inorganic mercury

Neurotoxicity

Brain morphometry

Motor behavior

Mood/anxiety-like behavior

Fish

\begin{abstract}
A B S T R A C T
The current study contributes to fill the knowledge gap on the neurotoxicity of inorganic mercury (iHg) in fish through the implementation of a combined evaluation of brain morphometric alterations (volume and total number of neurons plus glial cells in specific regions of the brain) and swimming behavior (endpoints related with the motor activity and mood/anxiety-like status). White seabream (Diplodus sargus) was exposed to realistic levels of $\mathrm{iHg}$ in water $\left(2 \mu \mathrm{g} \mathrm{L}^{-1}\right)$ during 7 (E7) and 14 days (E14). After that, fish were allowed to recover for 28 days (PE28) in order to evaluate brain regeneration and reversibility of behavioral syndromes. A significant reduction in the number of cells in hypothalamus, optic tectum and cerebellum was found at E7, accompanied by relevant changes on swimming behavior. Moreover, the decrease in the number of neurons and glia in the molecular layer of the cerebellum was followed by a contraction of its volume. This is the first time that a deficit on the number of cells is reported in fish brain after iHg exposure. Interestingly, a recovery of hypothalamus and cerebellum occurred at E14, as evidenced by the identical number of cells found in exposed and control fish, and volume of cerebellum, which might be associated with an adaptive phenomenon. After 28 days post-exposure, the optic tectum continued to show a decrease in the number of cells, pointing out a higher vulnerability of this region. These morphometric alterations coincided with numerous changes on swimming behavior, related both with fish motor function and mood/anxiety-like status. Overall, current data pointed out the iHg potential to induce brain morphometric alterations, emphasizing a long-lasting neurobehavioral hazard.
\end{abstract}

(c) 2015 Elsevier B.V. All rights reserved.

\section{Introduction}

Fish brain was demonstrated to be a target organ for mercury compounds, mainly methylmercury (MeHg). This $\mathrm{Hg}$ counterpart can easily cross the blood-brain-barrier (BBB), reaching the brain where it exerts toxicity (Farina et al., 2013). Conversely, so far, little is known about the neurotoxicity of inorganic mercury (iHg) in fish. Rouleau et al. (1999) postulated that the BBB is relatively

\footnotetext{
* Corresponding author.

E-mail address: pkpereira@ua.pt (P. Pereira).

1 Shared first authorship.

2 Shared senior authorship.
}

impervious to $\mathrm{iHg}$, working as a protective barrier against this $\mathrm{Hg}$ form. However, $\mathrm{iHg}$ compounds (e.g., $\mathrm{HgCl}_{2}$ ) can act as a direct $\mathrm{BBB}$ toxicant, increasing thus its permeability in rodents (Zheng et al., 2003). In fact, iHg was able to reach fish brain after three days of exposure to environmentally realistic levels in water (Pereira et al., 2015). This is in line with other studies that documented the occurrence of iHg in the brain of fish (Berntssen et al., 2003; Mieiro et al., 2010; Korbas et al., 2011; Wang et al., 2015).

The prevalence of information on $\mathrm{MeHg}$ is likely based in the perception of its higher toxicity associated with a rapid uptake and distribution. Nevertheless, it has been also stated that the different forms of $\mathrm{Hg}$ share the same toxic chemical entity (De Flora et al., 1994) and, thus, neurotoxicity may depend mainly on the exter- 
nal bioavailability. For instance, $\mathrm{iHg}\left(\mathrm{as} \mathrm{HgCl}_{2}\right)$ appeared somewhat more toxic than $\mathrm{MeHg}$ to glial cells and neurons in immature aggregate cultures of rat telencephalon (Monnet-Tschudi et al., 1996). Furthermore, the majority of $\mathrm{Hg}$ in natural waters occurs in inorganic forms, while MeHg often contributes to less than $5 \%$ of the total waterborne $\mathrm{Hg}$ (Watras et al., 1998). In the light of such evidences, the neurotoxicity of $\mathrm{iHg}$ in fish is worthy of investigation. Such relevance is consubstantiated by the fact that MeHg can be demethylated in the brain, leading to iHg retention over time (Vahter et al., 1995; Allen et al., 2002). Autopsy samples taken years after exposure to $\mathrm{MeHg}$ revealed that inorganic species account for most of the remaining $\mathrm{Hg}$ in monkeys' brain (Charleston et al., 1995). It has been suggested that the long residence time of $\mathrm{iHg}$ in the brain is due to the formation of an insoluble complex with selenium (WHO, 1990).

Only a few neurotoxicological endpoints have been employed to evaluate the biological effects of $\mathrm{iHg}$ in fish, both in laboratory experiments (Berntssen et al., 2003; Wang et al., 2011) and under field exposures (Mieiro et al., 2011). Both Berntssen et al. (2003) and Mieiro et al. (2011) searched for changes in oxidative stress profiles, while Wang et al. (2011) assessed alterations in the protein expression. Moreover, a histopathological examination of fish brain was performed by Berntssen et al. (2003), revealing a widespread neuronal degradation as an effect of $\mathrm{iHg}$ deposition. Such evidences are in line with observations in the brain of mammals exposed to iHg, either humans (Eto, 1997) or rodents (Fujimura and Usuki, 2012). Apoptosis is a key mechanism of neuronal destruction in degenerative brain damage and it has been widely related with $\mathrm{Hg}$ exposure, mainly MeHg (Aschner and Ceccatelli, 2010; Aschner et al., 2013). For instance, the accumulation of $\mathrm{Hg}$ in glial cells leads to apoptosis, thus, contributing to neuronal degeneration (Ohgoh et al., 2000). Moreover, the exposure of a developing rat brain to $\mathrm{iHg}$ elicited a rapid inhibition of cell proliferation, particularly in the hippocampus and cerebellum, two regions of postnatal neurogenesis (Burke et al., 2006). In contrast, iHg led to a significant increase in the number of reactive glial cells in monkeys (Charleston et al., 1994). This study also revealed a significant increase in the volume of brain regions of iHg treated monkeys, possibly related with edema (Charleston et al., 1994). Despite iHg triggered apoptosis of rodents' neuronal cells and interfered with regeneration of brain cells, fish were never examined for such processes. In this context, the assessment of brain morphometric alterations in specific brain regions upon $\mathrm{iHg}$ exposure could provide, for the first time, an indication of potential brain degradation and regeneration.

Behavioral changes are widely described as an integrated manifestation of biochemical and structural disturbances (Scott and Sloman, 2004). As previously stated, certain anatomical regions of the rodents' brain seemed to be more vulnerable to iHg exposure, namely cerebellum and brain stem (Møller-Madsen and Danscher, 1986). Structural alterations in those regions regulating the motor system could lead to neurobehavioral impairments (e.g., ataxia, paresthesia, insomnia, tremors) in humans and wildlife (reviewed by ATSDR, 1999). In fact, the motor function of rats was compromised after exposure to $\mathrm{iHg}$, as demonstrated by the negative geotaxis and beaker test (Moraes-Silva et al., 2014). Moreover, the chronic exposure to $\mathrm{iHg}$ can impair memory formation in rats, leading to a deficit on object recognition and aversive memories (Mello-Carpes et al., 2013). Fish exposure to iHg provided contrasting results, namely on the Atlantic salmon where no alterations were found on overall activity (Berntssen et al., 2003), while Pomatoschistus microps exhibited a reduced ability to swim (Vieira et al., 2009). In addition, Vieira et al. (2009) found concentrationdependent effects on swimming resistance and covered distance at concentrations equal or higher than $3 \mu \mathrm{g} \mathrm{L}^{-1}$.

The evaluation of swimming performance is considered a paradigmatic endpoint of the fish motor status that is being widely used to evaluate neurobehavioral effects of aquatic contaminants (e.g., Little and Finger, 1990; Vieira et al., 2009; Almeida et al., 2010). In addition, the evaluation of the anxiety-like status of fish has been recently proposed to assess behavioral effects of toxic substances (Maximino et al., 2010, 2012). Though Hg was never associated with such symptoms in fish, human epidemiological studies established a relationship between $\mathrm{Hg}$ accumulation and depression (Wojcik et al., 2006), a major mood alteration.

According to Korbas et al. (2010), the accumulation of $\mathrm{Hg}$ in brain of fish does not imply per se toxicity, which can be partially related to the chemical form of $\mathrm{Hg}$ in the cells and protection mechanisms. Particularly, iHg can be stored as $\mathrm{Hg}$ selenide (HgSe) that is considered an inert nontoxic form (Korbas et al., 2010). Nevertheless, $\mathrm{iHg}$ can induce effects in the brain by causing a deficiency of essential Se-dependent enzymes, which is an indirect mechanism of $\mathrm{iHg}$ toxicity called the "selenium depletion hypothesis" (Korbas et al., 2010). Hg deposits were located exclusively in the lysosomes of brain cells of rats exposed to $\mathrm{HgCl}_{2}$ and presented as a sequestration strategy (Møller-Madsen and Danscher, 1991).

The neurotoxicity of $\mathrm{iHg}$ in fish was never assessed by a comprehensive approach, comprising brain morphometric and behavioral evaluations. Hence, this study tackles the impact of $\mathrm{iHg}$ in the brain of fish (white seabream-Diplodus sargus) by the implementation of such approach. The study aims to clarify in what extent $\mathrm{iHg}$ accumulation induces morphometric alterations and impairment of swimming behavior, as well as the processes of brain recovery and reversibility of behavior alterations along with iHg depuration. Thus, a combined approach was designed to answer these questions, comprising: (i) stereological evaluation of the total number of cells (neurons plus glia) and volume of specific regions of the encephalon (medial and lateral pallia, optic tectum, hypothalamus and cerebellum); (ii) assessment of fish swimming behavior through diverse exploratory endpoints that include the evaluation of motor performance and potential mood/anxiety-like status of fish. Fish were surveyed after 7 and 14 days of iHg exposure, as well as after a 28 days post-exposure period. A realistic waterborne $\mathrm{Hg}$ concentration was tested $\left(2 \mu \mathrm{g} \mathrm{L}^{-1}\right)$ in order to produce reliable data for environmental health assessment. The exposure level is comparable to those found in contaminated water of rice fields in China $\left(1.5 \mu \mathrm{g} \mathrm{L}^{-1}\right.$ ) (Horvat et al., 2003) or during a flooding event in Kazakhstan (ranging between 1.6 and $4.3 \mu \mathrm{g} \mathrm{L}^{-1}$ ) (Li et al., 2009).

\section{Material and methods}

\subsection{Experimental set-up}

The white seabream $D$. sargus was selected as a test organism since it is an abundant fish in estuarine systems, where Hg contamination is a frequent scenario (Pereira et al., 2009). In this context, D. sargus was previously employed to investigate the toxicokinetics of iHg (Pereira et al., 2015). Moreover, it is effortlessly maintained in the laboratory and is easy to handle, which is an important trait to perform behavior studies.

Juvenile specimens (sexually immature) were used in the experiment, provided by an Aquaculture Research Station (IPMA-Olhão, Portugal), from the same cohort (weight: $146 \pm 14 \mathrm{~g}$; total length: $19 \pm 1 \mathrm{~cm}$ ). At this stage of development, $D$. sargus have an undifferentiated gender. Fish were kept in 300 L fiberglass taperedcylindrical tanks with an average initial density of $0.0068 \mathrm{~kg} \mathrm{~L}^{-1}$, under a 10:14 light:dark photoperiod. A total of 12 tanks with the same characteristics were used in the experiment ( 6 for control condition and 6 for exposure to $\mathrm{iHg}$ ). Each tank contained at the beginning of the experiment a total of 14 individuals. All tanks were placed in the same aquaria room. Seawater was renewed daily (around 80\%) and fish were fed once a day with a commer- 
cial dry food [standard $3 \mathrm{~mm}$ from Sorgal (Portugal)], $1-2 \mathrm{~h}$ before water renewal. Total $\mathrm{Hg}$ levels in food pellets were lower than $0.01 \mu \mathrm{g} \mathrm{g}^{-1}$. On the sampling days, fish were not fed in the $12 \mathrm{~h}$ preceding fish handling. Water temperature, salinity, dissolved oxygen and $\mathrm{pH}$ were monitored daily throughout the experiment, varying as follows, respectively: $13.5 \pm 0.3^{\circ} \mathrm{C}, 35 \pm 2,6.28 \pm 0.6 \mathrm{mg} \mathrm{L}^{-1}$ and $7.0 \pm 0.5$ (mean values in all 12 tanks). Control fish were kept throughout the experiment in tanks filled with clean seawater that was renewed every day, as described.

Prior to Hg exposure, fish were allowed to acclimatize to experimental conditions and routines for two weeks. Fifteen fish were sacrificed at the beginning of the experiment and used as the initial reference group (time zero; T0) ( $n=5$ for brain morphometric analyses and $n=10$ for evaluation of fish swimming behavior) (Fig. 1).

Mercury was added to the water of the exposure tanks from a standard solution of $\mathrm{Hg}\left(1000 \mathrm{mg} \mathrm{L}^{-1}, \mathrm{Hg}^{2+}\right)$ of Sigma-Aldrich in order to reach a final concentration of $2 \mu \mathrm{g} \mathrm{L}^{-1}$ (nominal concentration). $\mathrm{Hg}$ was added on a daily basis after water renewal i.e. daily water recontamination. The standard solution of $\mathrm{Hg}$ was maintained at $4{ }^{\circ} \mathrm{C}$ throughout the exposure period. The $\mathrm{Hg}$ concentration tested $\left(2 \mu \mathrm{g} \mathrm{L}^{-1}\right)$ was established considering previous studies in contaminated areas (Horvat et al., 2003; Li et al., 2009) in order to mimic environmentally realistic conditions. Moreover, the Environmental Protection Agency established a maximum contaminant level goal for $\mathrm{Hg}$ in drinking water of $2 \mu \mathrm{g} \mathrm{L}^{-1}$, meaning that safety levels for human health need to be below this value (EPA, 2015).

Fish wellbeing deserved a permanent attention, in accordance with national and international guidelines for the protection of animal welfare, namely with the ethical guidelines of the European Union Council (Directive 2010/63/EU). Moreover, two of the coauthors are authorized by the competent Portuguese authorities to perform animal experiments.

Fish were exposed to $\mathrm{iHg}$ for 7 (E7) and 14 (E14) days. Thereafter, fish were maintained in clean water (post-exposure) provided by a flow-through system and in the same tanks used for exposure (Fig. 1). In each sampling time point, a total of 15 fish were sampled per condition, being divided by the different components of the study as follows: $n=5$ for brain morphometric analyses; $n=10$ for fish behavioral evaluation. The experiment had a total duration of 42 days.

During the exposure period (at days 1, 3, 7 and 14), water samples were collected in triplicates, from exposure and control tanks, $24 \mathrm{~h}$ after recontamination to quantify total $\mathrm{Hg}(\mathrm{tHg})$ levels. Values of tHg in the exposure tanks varied between 0.05 and $0.36 \mu \mathrm{g} \mathrm{L}^{-1}$, which would correspond to the minimum exposure concentration. Levels of $\mathrm{tHg}$ in the control tanks were always below the detection limit throughout the experiment $\left(<0.1 \mathrm{ng} \mathrm{L}^{-1}\right)$. Identically, at day 42 (post-exposure period), both in control and in previously contaminated tanks, tHg was below the analytical detection limit.

\subsection{Brain collection}

Fish used for stereological measurements were anesthetized immediately after collection with tricaine methanesulfonate (MS222) during approximately $15 \mathrm{~min}$ that was the time required to fish loss its equilibrium and to become "handleable", as previously defined (Gilderhus and Marking, 1987). Then, fish were weighed, measured, and sacrificed by cervical transection. Fish were properly bled and whole brain (comprising rostral and caudal portions) was removed, and immersed in a solution of $4 \%$ paraformaldehyde in phosphate-buffered saline ( $\mathrm{pH} 7.4$ ) for a minimum of $72 \mathrm{~h}$, with no rinses. The brains were then dehydrated via graded concentrations of ethanol and embedded in glycolmethacrylate resin, using a Technovit 7100 embedding kit (Heraeus Kulzer GmbH, Werheim, Germany).

\subsection{Morphometric analyses of brain regions}

Each brain was serially sectioned $(30 \mu \mathrm{m})$ in the coronal plane with a rotating microtome (Leica, Germany) and collected on superfrost slides (4951PLUS4; Thermoscientific, USA). The brain sections were stained with Giemsa's azur eosin methylene blue solution (Merck, Darmstadt, Germany) at 20\% concentration for $15 \mathrm{~min}$, mounted with Entellan New (Merck, Darmstadt, Germany) and coverslipped.

Observations covered all encephalon areas (telencephalon; diencephalon; mesencephalon; rhombencephalon) but specific zones were selected within each area considering their key roles in controlling neurobehavioral functions, namely the medial and lateral pallia, hypothalamus, optic tectum and cerebellum. To the best of our knowledge, no brain atlas was published concerning D. sargus' brain anatomy. Hence, the identification of these brain regions was performed by comparison with the brain atlas of the gilthead seabream Sparus aurata (Muñoz-Cueto, 2001), which also belongs to the Sparidae family, and the boundaries of the brain regions were established based on their cytoarchitecture (Fig. 2). In this study, cerebellum refers only to the molecular cell layer of both the valvula and corpus cerebelli. The molecular cell layer consists mainly of nerve fibers and inhibitory stellate cells (Ikenaga, 2013; Kaslin and Brand, 2013). The stellate cells receive excitatory inputs from parallel fibers and provide GABAergic inhibitory inputs to dendrites of the Purkinje cells. In this way, the inhibitory interneurons can modulate motor coordination and are essential for motor and associative learning, and therefore are important for information processing in the cerebellum (Kaslin and Brand, 2013; Liu, 2013). Additionally, it is within the molecular layers of the cerebellum that are harbored the stem cells, which contribute to the potential of the intact brain to generate new neurons continuously, and to the injured brain to replace damaged cells by newly generated ones (Zupanc, 2008; 2009; Zupanc and Sîrbulescu, 2013).

The Cavalieri method (Gundersen and Jensen, 1987; Gundersen et al., 1988; West, 2012) was used to estimate the volume of the lateral pallium, medial pallium, hypothalamus, optic tectum, and cerebellum. The Cavalieri estimator of the volume of an object is based on the areas of the sectional profiles of an object seen in a series of parallel sections cut at uniform intervals through the object (West, 2012). Hence, using the StereoInvestigator software (MicroBrightField, Williston, VT, USA) and a camera (DXC390; Sony, Tokyo, Japan) attached to a motorized microscope (Axioplan 2; Zeiss, Oberkochen, Germany), the contours of the brain regions were drawn using a 2.5x Plan-Neofluar objective (N.A. 0.075), at the final magnification of $25 \mathrm{x}$, to obtain their cross sectional areas. Throughout the whole brain one in every 8 sections was delimitated and analyzed, yielding a distance of $240 \mu \mathrm{m}$ between sections. The first section was selected randomly within the first eight sections.

The number of both neurons and glial cells in each brain region was estimated using the optical fractionator technique (West et al., 1991; Sørensen et al., 2000; Keuker et al., 2001; West, 2013a,b). The optical fractionator is a combination of (i) the fractionator sampling, a scheme involving the probing of a known fraction of the tissue, and (ii) the optical disector, which is a three-dimensional probe used for counting cells. With the optical fractionator sampling scheme, no information on the size of the brain region or the magnification of the microscope is needed, and it is independent of tissue's swelling and/or shrinking during processing. Following the delimitation of the brain regions for volume estimation, the neurons and glia were counted on thin focal plane scanning in the $Z$ axis, using a 100x Plan-Neofluar oil objective (N.A. 1.30) and a final magnification of 1000x. The StereoInvestigator software positioned 


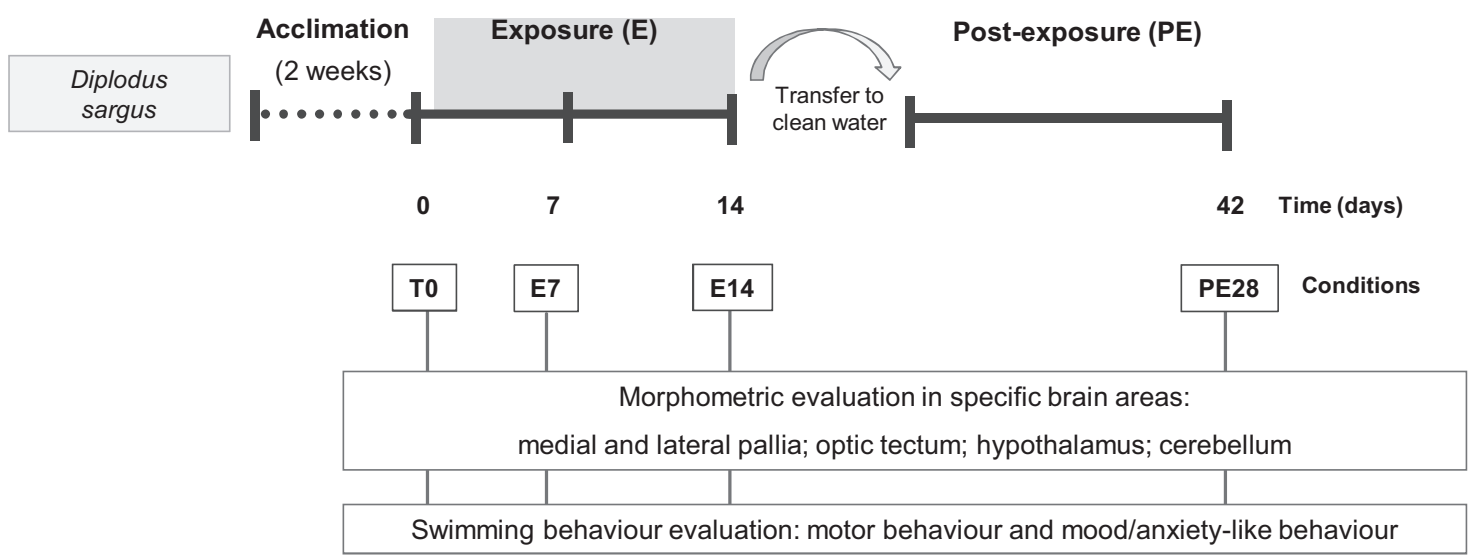

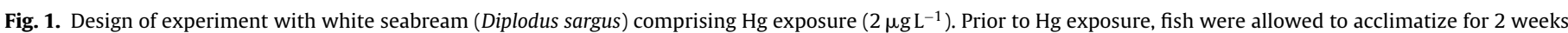

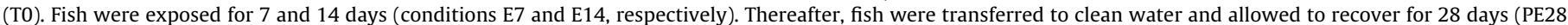
condition). In parallel, control groups were also considered.

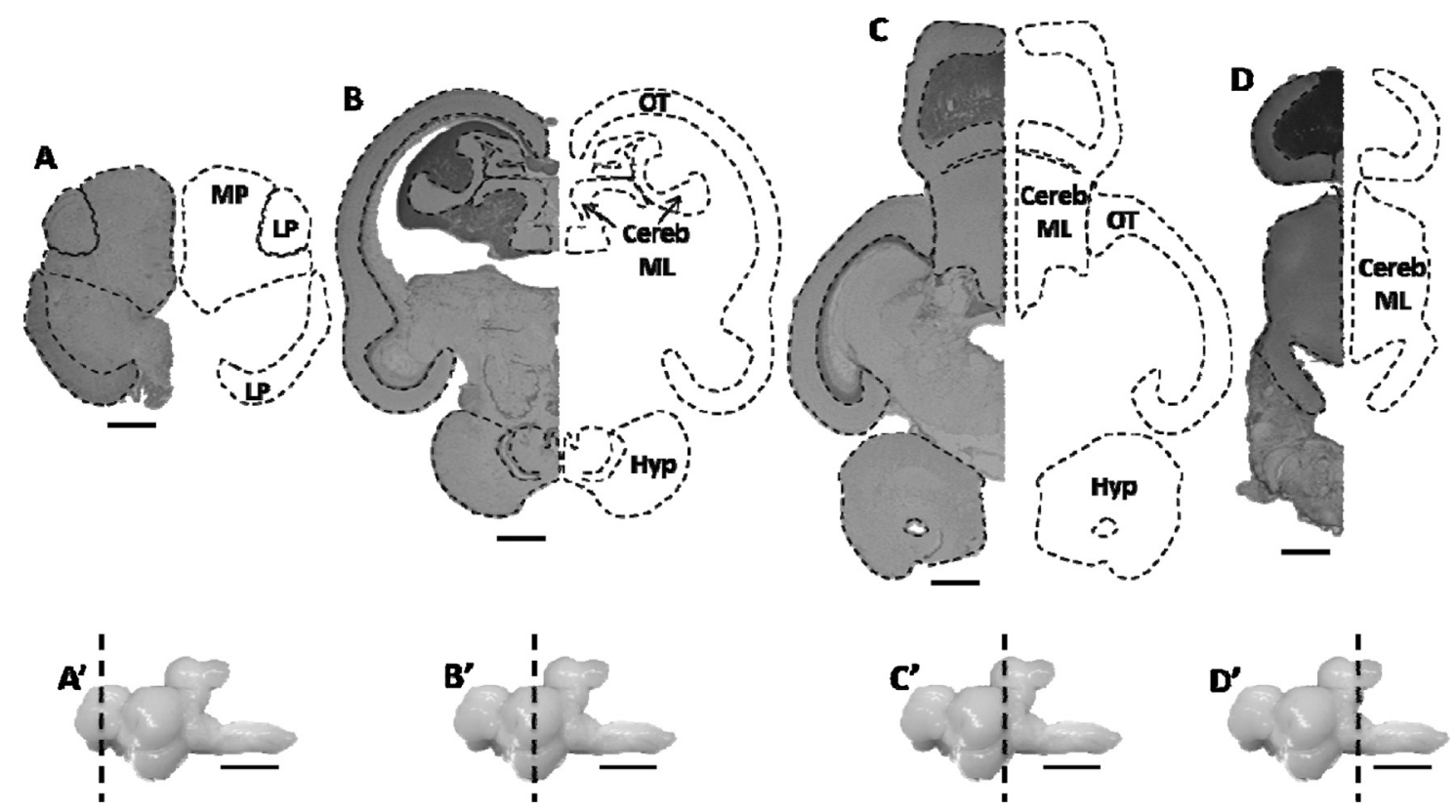

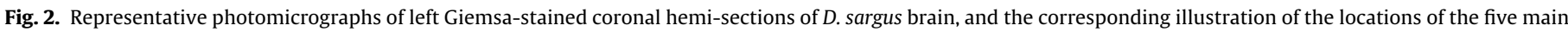

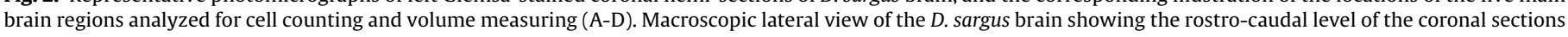

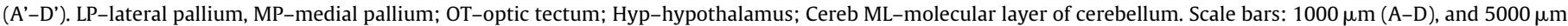
$\left(A^{\prime}-D^{\prime}\right)$. (For interpretation of the references to color in this figure legend, the reader is referred to the web version of this article.)

the optical disectors systematically and randomly on each of the sampled sections at regular predetermined $x, y$-positions to ensure that all parts of the brain region had an equal probability of being sampled. The $x$ and $y$ step sizes of the mesh grid that define the disector positions were the following: $500 \times 500 \mu \mathrm{m}$ in lateral pallium, medial pallium and hypothalamus; $550 \times 550 \mu \mathrm{m}$ in optic tectum; $600 \times 600 \mu \mathrm{m}$ in cerebellum (the molecular layer of both corpus cerebelli and valvula cerebelli were studied as one). The dimensions of the optical disector were $30 \times 30 \mu \mathrm{m}$, and $20 \mu \mathrm{m}$ height in all brain regions, and a guard zone of $5 \mu \mathrm{m}$ above the disector box. Cells were counted when the nucleus, in the case of neurons, or the cell profile, in the case of glia, came into focus, within the optical disector or intersected the inclusion planes without touching the exclusion planes on the unbiased counting frame. High magnification photomicrographs with examples of typical neuronal and glial morphologies, representative of each brain region analyzed, are present in Fig. 3B. All fish were blind coded to eliminate any bias by the experimenter.
During the counting procedure, no distinction was made between neurons and glial cells. Although the larger neurons, with their perikarya and nucleus with nucleoli, can be easily separated from the smaller and numerous glial cells, with round nucleus, which are usually identified as oligodendrocytes, the same might not be true for neurons of smaller dimensions and larger glial cells (astrocytes) (Nielsen et al., 2011; Hou et al., 2012). Thus, it was decided to evaluate changes in the number of total cells (neurons plus glial cells).

Both the volume and the total cell number (neurons and glial cells) of bilateral brain regions, such as the lateral and medial pallia, hypothalamus and optic tectum, were estimated in the right and left hemispheres and the values presented as the average of both hemispheres. For the cerebellum, the total volume and cell number of the molecular layer were estimated as a whole due to its central localization in the brain. 
A
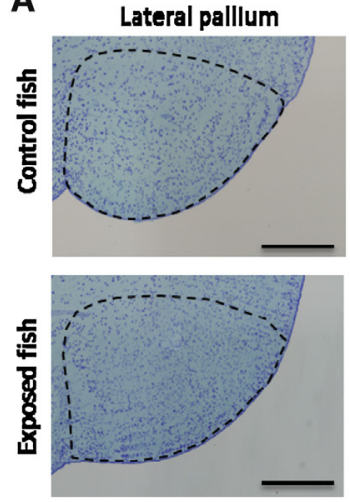

B
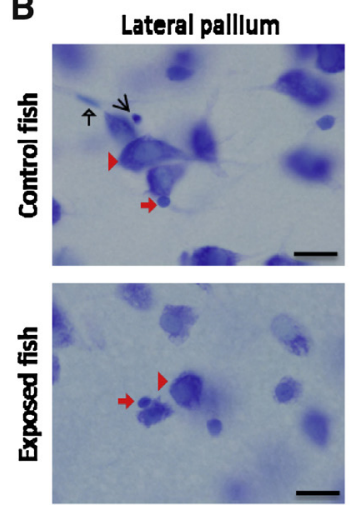

Medlal palllum
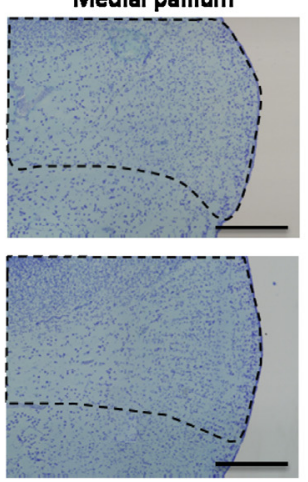

Medlal palllum
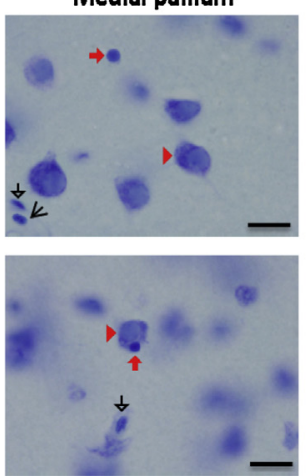

Hypothalamus
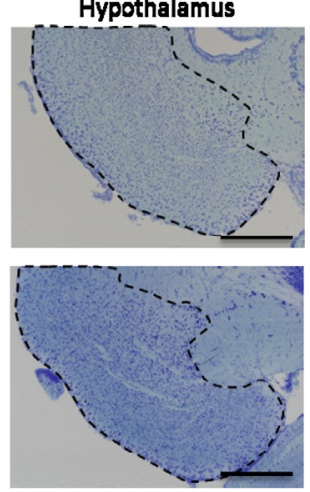

Hypothalamus
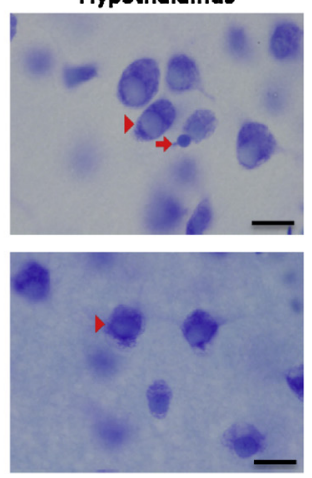

Optlc tectum
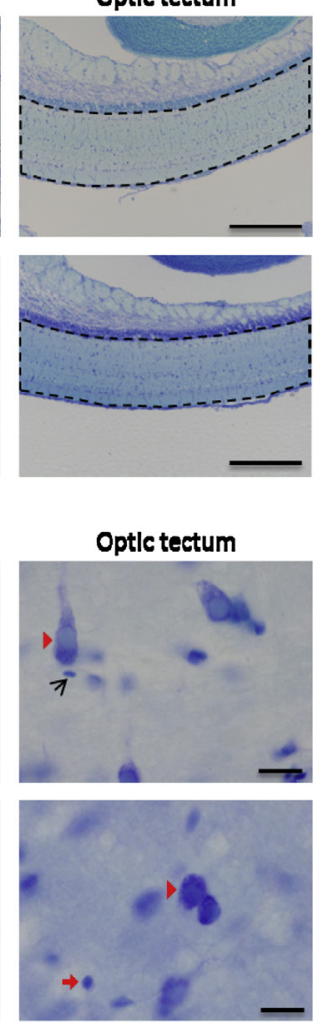

Cerebellum
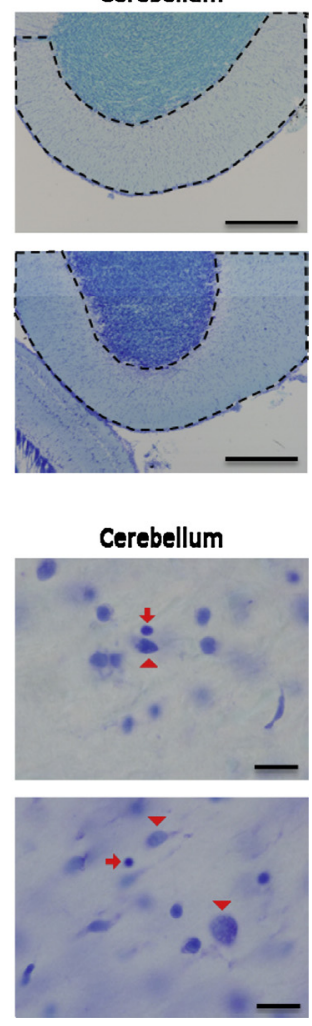

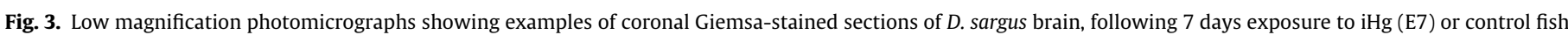

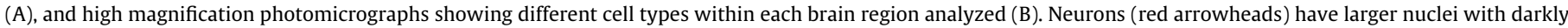

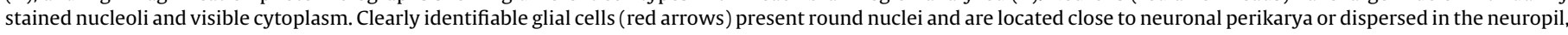

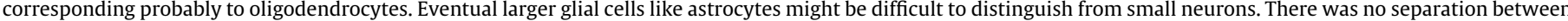

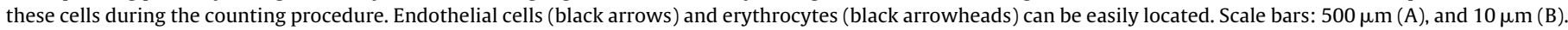

\subsection{Photomicrographs}

The representative photomicrographs of the coronal sections (Fig. 2 A-D) were captured with a digital camera (Olympus Sc30) mounted on Olympus SZX7 zoom stereo microscope, and using the Cell-P software (Olympus, Germany). The photograph of lateral view of a whole brain of $D$. sargus (Fig. 2 A'-D') was shot with a digital camera (Sony Handycam DCR-SR52). The photomicrographs of stained sections in Fig. 3A and B were shot with a digital camera (Olympus DP) mounted on an Olympus BX61 microscope (Olympus, Germany) with a 4x (UPlan SApO, N.A. 0.16) objective or 100x (UPlan SApO, N.A. 1.4) oil objective, using the Cell-P software (Olympus, Germany).

\subsection{Evaluation of fish swimming behavior}

At each sampling time point, fish were caught individually and randomly, rapidly transported in a 10 -L bucket into the behavioral test room, and immediately introduced into the behavior evaluation device (BED) (Fig. 4). The BED consists in a $4 \mathrm{~m}$ long polypropylene tube (transparent) with a metric scale (every $10 \mathrm{~cm}$ ), $30 \mathrm{~cm}$ diameter, and a refuge area (black polypropylene tube) in the extreme A (Fig. 4). All fish were handled in a consistent manner and introduced in the BED, close to the water outlet, in the same position, i.e., placed vertically and with the head against the water flow. Then, fish were allowed to swim against a non-contaminated water flow of $150 \mathrm{~L} \mathrm{~min}^{-1}$. Unnecessary movements or noise were avoided during the tests. The white seabream has a vigorous swimming activity, making it suitable to the evaluation by the designed BED, which allows fish to swim against a strong water flow. This premise is in line with Hernández-Moreno et al. (2011) and Gravato and Guilhermino (2009) that performed an identical assessment of sea bass (Dicentrarchus labrax) swimming behavior.

The swimming behavior of each fish was videotaped (Sony Handycam DCR-SR52) by an experimenter placed $4 \mathrm{~m}$ away from the BED, during $3 \mathrm{~min}$, for posterior visualization and analysis. Several endpoints were registered during the behavior tests and further confirmed after the video examination. These endpoints were divided in two major branches, i.e., those concerned mainly with motor aspects and the ones evaluating fine aspects related with the mood/anxiety-like behavior of fish.

Motor performance:

- First run distance ( $m$ )-distance that each fish swims (from A to B; see Fig. 4) against the water flow in the first run (until being immobilized or dragged for the first time by the water flow);

- First run time (s)-time spent on the first run;

- First run velocity $(\mathrm{m} / \mathrm{s})$-calculated by dividing the first run distance $(\mathrm{m})$ by the respective run time $(\mathrm{s})$;

- Swimming frequency-number of times that fish swam actively (at least $10 \mathrm{~cm}$ ) during the $3 \mathrm{~min}$ of the test, independently of the swimming direction;

- Total swimming distance (m)-total distance swam during the test ( $3 \mathrm{~min}$ ), obtained by summing all runs, independently of the swimming direction;

- Total swimming time (s)-time spent swimming actively (displacement $\neq 0$ ) during the test.

Mood/anxiety-like signs: 


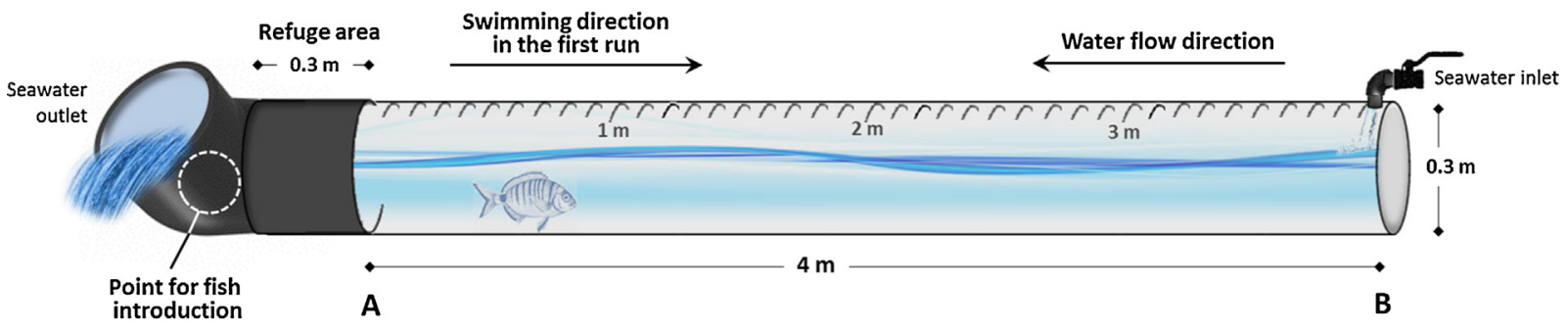

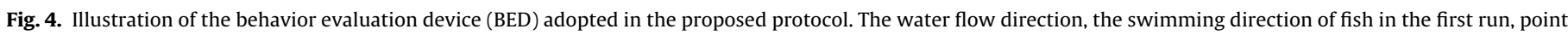
for fish introduction, refuge area, as well as the tube extremes, corresponding to the seawater outlet (A) and inlet (B), are represented.

- Refuge latency (s)-time elapsed until fish hid in the refuge area;

- Immobility latency (s)-time spent swimming until immobilization for at least $3 \mathrm{~s}$;

- Dragging latency (s)-period of time swimming until being dragged towards the dragging zone, which was considered to be the half of the tube farther from the water inflow (in the latter $2 \mathrm{~m}$ towards the extreme A of the tube; see Fig. 4).

It should be noticed that fish sometimes do not attain all the endpoints. For example, if the fish swims continuously until refuge in the dark area, the time to be dragged, time for immobilization and time to refuge are the same for statistical purposes; additionally, if the fish does not take refuge or does not stop swimming, the immobilization latency, the dragging latency and the refuge latency are considered to be the time limit of the test, $3 \mathrm{~min}$.

All the tests were performed between $12: 00 \mathrm{~h}$ and 16:00 h, since the white seabream has been described as a diurnally active fish, influenced by light intensity (Figueiredo et al., 2005; Abecasis et al., 2013). After testing, fish were removed carefully from the BED and transferred to a discard tank. Discarded animals were not used in any another evaluation (morphometric or behavioral).

The device construction and the selection of endpoints were based on a previous work performed with fish (Vieira et al., 2009). However, the behavioral approach implemented in the current study was more complete than the previous one, by including several new endpoints related both with fish motor function and its potential mood/anxiety-like status. These were based on an adaption of endpoints of standardized behavioral tests performed in fish to evaluate exploitation-based anxiety-like behavior (Maximino et al., 2012), and in rats to evaluate depressive-like (forced swimming test) behavior (Sousa et al., 2006; Slattery and Cryan, 2012).

\subsection{Data analysis}

GraphPad software (GraphPad Prism version 6.01 for Windows, GraphPad Software) was used to perform the statistical analyses. All data were firstly tested for normality (Shapiro-Wilk test) and homogeneity of variance (Brown-Forsythe test). The differences between control and exposed fish at each sampling time were assessed using an unpaired Student's $t$-test with a significance level of 0.05 (two-tailed). If a discrete variable was present, a nonparametric Mann-Whitney $U$-test (two-sided, unpaired) was employed. The results were considered to be statistically different when $p<0.05$ and data are presented as mean \pm standard error of the mean (SEM).

\section{Results}

No fish mortality was observed during the experiment. Though feeding was not strictly monitored, no alterations were perceptible during and after treatment on fish feeding behavior. Fish condition was assessed along the experiment through the Fulton's condition factor $(K)$, according to the expression $K=(W \times 100) / L^{3}$, where $W=$ weight $(\mathrm{g})$ and $L=$ total length $(\mathrm{cm})$. At E7, E14 and PE28 the condition factor of control $(2.2 \pm 0.06 ; 2.3 \pm 0.07 ; 2.2 \pm 0.09$, respectively) and exposed fish $(2.1 \pm 0.08 ; 2.3 \pm 0.07 ; 2.2 \pm 0.06$, respectively) showed no significant differences within each sampling time, being $K$ values also statistically similar to T0 fish $(2.2 \pm 0.08)$.

\subsection{Number of cells and volume of brain regions}

After 7 days of exposure to $\mathrm{iHg}$, a significant reduction in the total number of neurons plus glial cells in hypothalamus ( $t$-test, $p<0.001$ ), optic tectum ( $t$-test, $p=0.009$ ) and cerebellum ( $t$-test, $p=0.037$ ) (Fig. 5C-E) was found. No alterations in the number of cells were recorded after 14 days of exposure or in the post-exposure period (PE28) in the hypothalamus and cerebellum (Fig. 5C-E). Contrastingly, the optic tectum of exposed fish showed a lower number of brain cells than control after 14 days of exposure $(t$-test, $p=0.037)$ and in the post-exposure period ( $t$-test, $p=0.021$ ) (Fig. 5D). Moreover, the medial and lateral pallium did not show any alteration in the number of brain cells throughout the experiment (E7, E14 and PE28) (Fig. 5A and B).

A significant decrease in the cerebellum volume was found in exposed fish at E7, in comparison with control fish ( $t$-test, $p=0.004$; Fig. 5E'). No significant volume alterations were found on medial and lateral pallium, hypothalamus and optic tectum during exposure to $\mathrm{iHg}$ (E7 and E14) and in the post-exposure period (PE28) (Fig. 5A'-D').

\subsection{Swimming behavior of fish}

In what concerns general motor behavior, fish exposed to $\mathrm{iHg}$ swam a smaller distance in the first run than controls after 7 days of exposure (E7) ( $t$-test, $p=0.025$; Fig. 6A). At this condition, exposed fish showed also a lower velocity in the first run ( $t$-test, $p=0.003$; Fig. 6C). No alterations were found on fish motor behavior after 14 days of exposure. At 28 days post-exposure (PE28), fish previously exposed still swam a smaller distance ( $t$-test, $p=0.015$; Fig. $6 \mathrm{~A}$ ) and during less time ( $t$-test, $p=0.002$; Fig. $6 \mathrm{~B}$ ) than controls in the first run. Additionally, at PE28 previously exposed fish swam less times (Mann-Whitney $U$-test, $p=0.005$; Fig. 6D) and a smaller distance ( $t$-test, $p=0.021$; Fig. $6 \mathrm{E}$ ) during the 3 min of observation than controls. No significant differences were found between exposed 
NUMBER OF CELLS

A

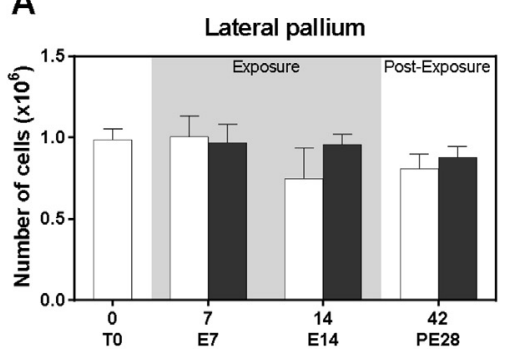

B

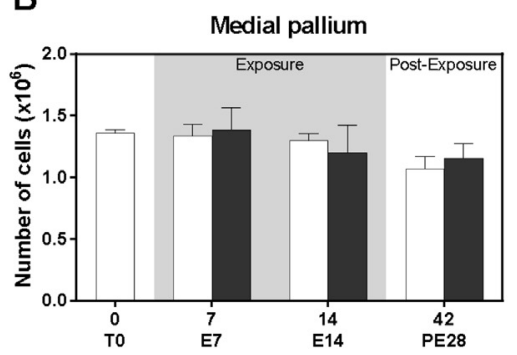

C

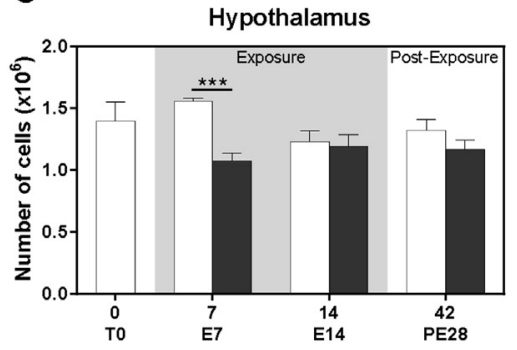

D

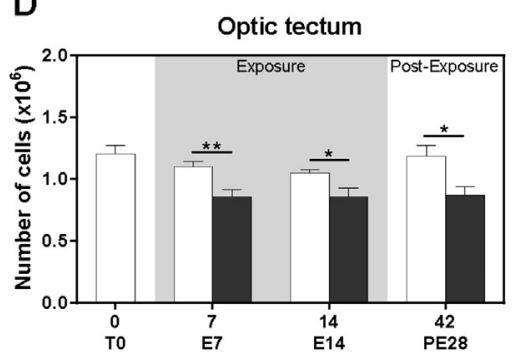

E

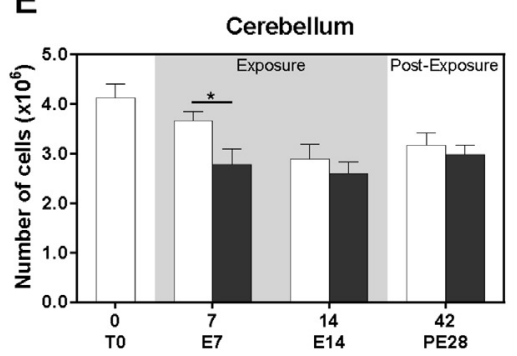

VOLUME OF BRAIN REGION

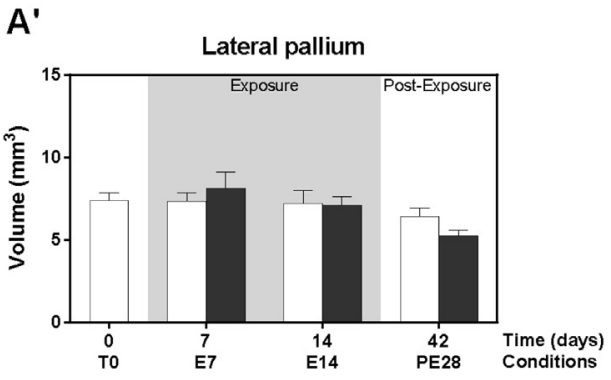

B'

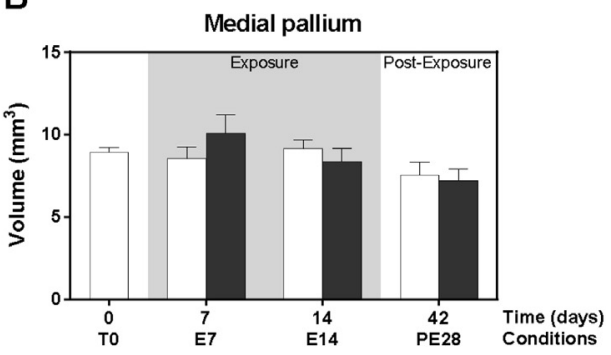

$C^{\prime}$
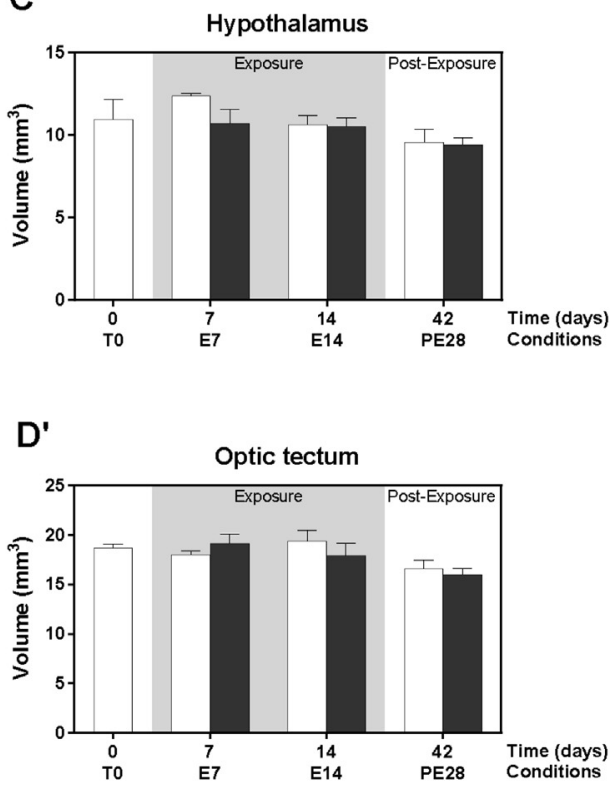

$E^{\prime}$

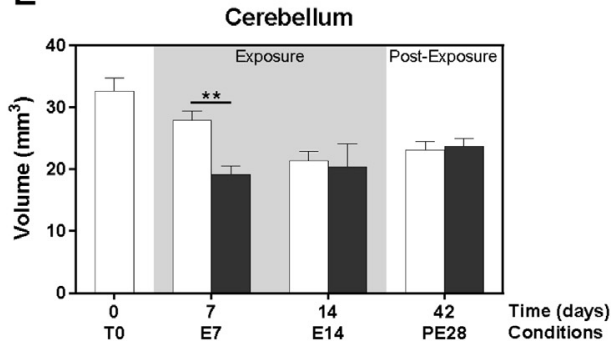

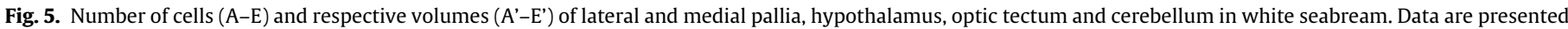

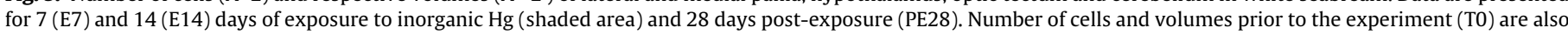

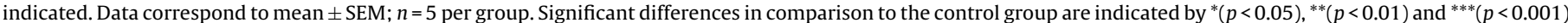
for each experimental time. 
A

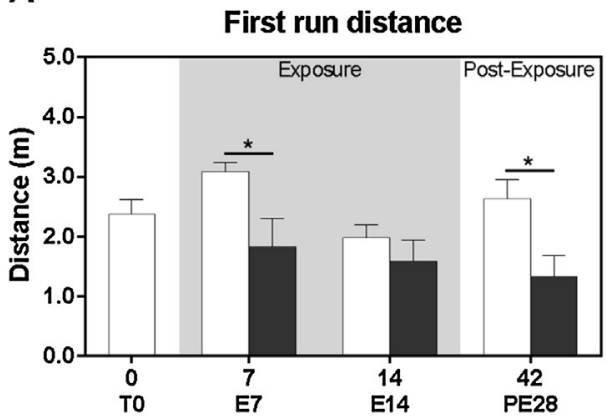

C

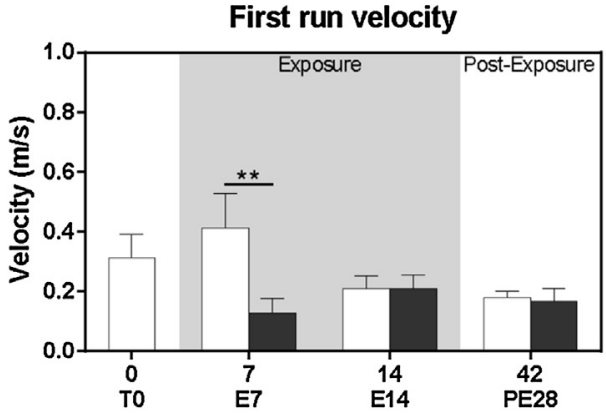

E

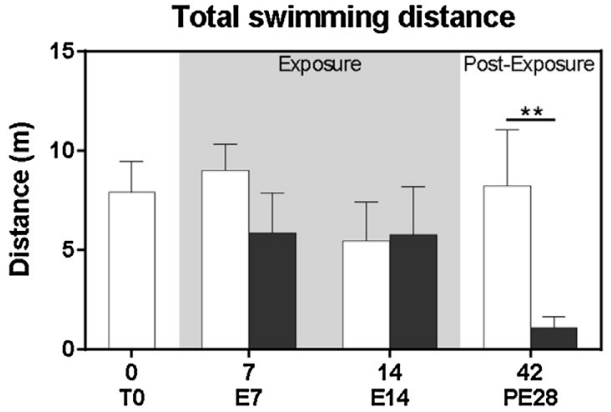

B

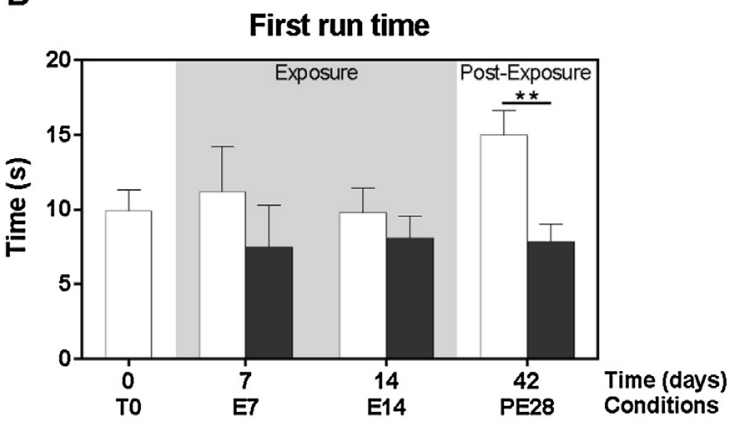

D

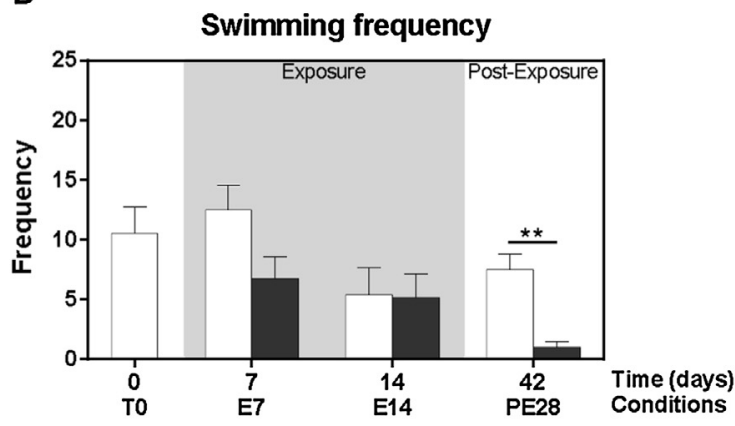

$\mathbf{F}$

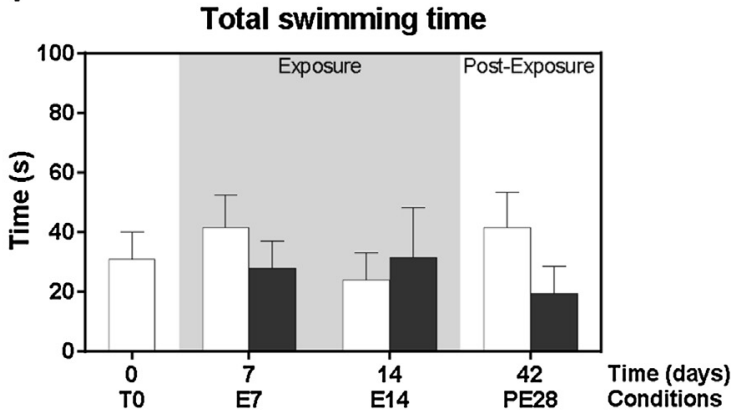

\section{Control fish Exposed fish}

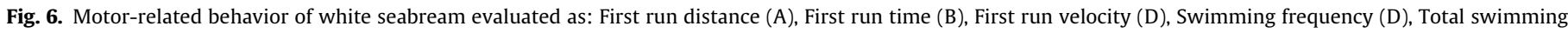

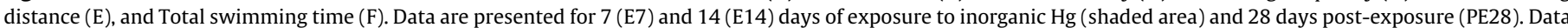

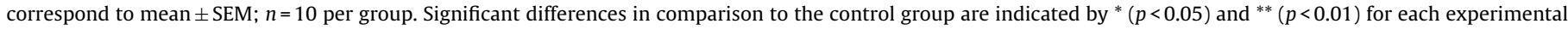
time.

fish and controls, during the entire experiment, regarding the total swimming time (Fig. 6F).

In what concerns the assessment of mood/anxiety-like behavior, fish exposed to iHg during 7 days showed alterations only in the time spent to take refuge on the dark area of BED, as they spent less time than controls to seek protection ( $t$-test, $p=0.024$; Fig. 7A). No alterations were found on fish mood/anxiety behavior after 14 days of exposure. Additionally, at PE28 previously exposed fish also spent less time to reach immobility ( $t$-test, $p=0.026$; Fig. $7 \mathrm{~B}$ ) and to be dragged ( $t$-test, $p=0.044$; Fig. $7 \mathrm{C}$ ) than controls.

\section{Discussion}

The current study pinpointed that harmful levels of iHg could reach fish brain after exposure to environmentally relevant concentrations in water, eliciting a significant loss of brain cells (neurons plus glial cells) in specific regions (hypothalamus, optic tectum and molecular layer of the cerebellum), a decrease of cerebellum volume (molecular layer) and the impairment of fish swimming behavior. This is the first time that a deficient number of cells is reported in the fish brain after $\mathrm{iHg}$ exposure. Unexpectedly, a recovery of several brain regions was observed at E14, when the maximum of iHg had reached the brain (Pereira et al., 2015), unveiling the potential occurrence of adaptive mechanisms. The hypothalamus and cerebellum kept a balanced condition in the post-exposure period, while the optic tectum showed higher vulnerability to iHg deposition by maintaining the loss of brain cells. The long-term effects of $\mathrm{iHg}$ were also disclosed by numerous alterations on motor and mood/anxiety-like behavior after 28 days of recovery. 
A

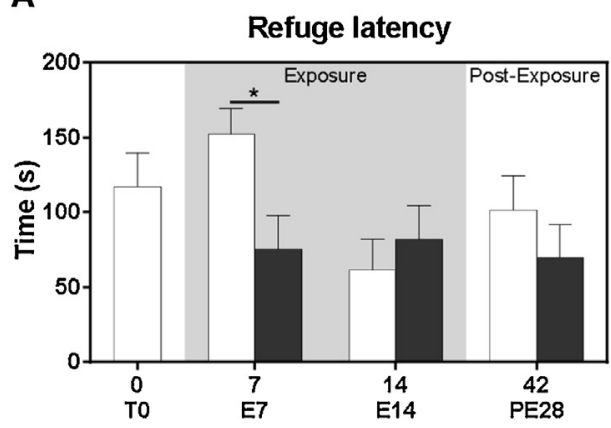

B

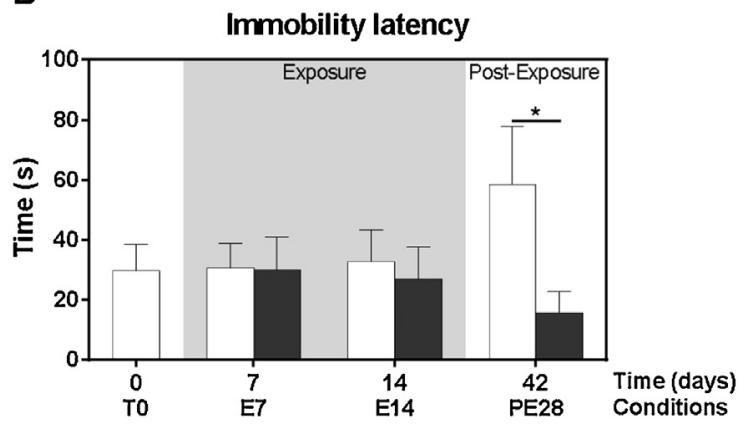

C

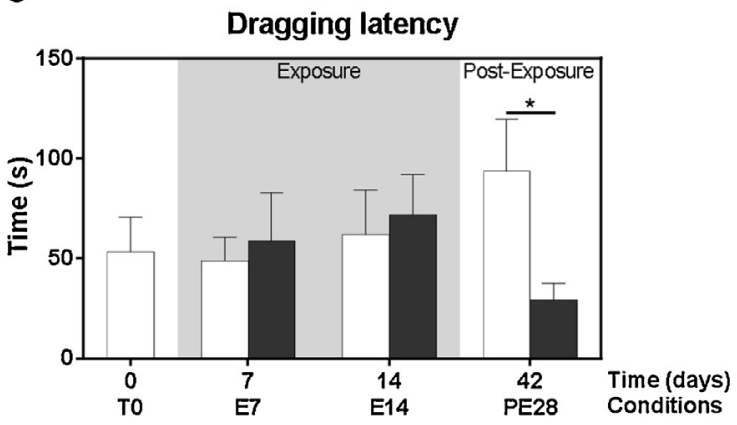

$\square$ Control fish
$\square$ Exposed fish

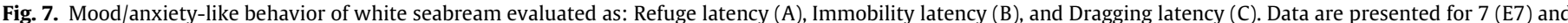

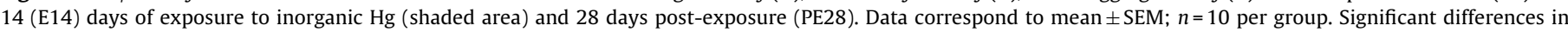
comparison to the control group are indicated by * $(p<0.05)$

\section{1. iHg-induced brain morphological alterations}

iHg elicited quantitative morphological alterations in specific brain regions of fish, namely in hypothalamus, optic tectum and cerebellum (molecular layer), indicating that those areas were targeted by this $\mathrm{Hg}$ form. In fact, in the exposure period, a significant decrease in the number of cells in those areas was only recorded on day 7. At this time, it was also found a relevant accumulation of $\mathrm{Hg}$ $\left(0.62 \mu \mathrm{g} \mathrm{g}^{-1}\right)$ in whole fish brain (Pereira et al., 2015). iHg enter the brain either through the bloodstream after crossing the BBB (Korbas et al., 2013) or by axonal transport following a direct sensory uptake from water (Rouleau et al., 1999). Pereira et al. (2015) did not evaluate the distribution of $\mathrm{iHg}$ by different brain regions mainly due to analytical restrictions, although a heterogeneous distribution of iHg was described for mammals' brain, being mostly accumulated in rhombencephalon while a lower deposition was found in telencephalon (Møller-Madsen and Danscher, 1991). Similarly, iHg was accumulated in specific areas of fish brain (olfactory system, cerebellum, optic nerve and tectum, and rhombencephalon) following exposure via water (Rouleau et al., 1999). A non-uniform distribution of iHg might also be currently hypothesized for the brain of white seabream. This would explain the occurrence of cell loss in hypothalamus, optic tectum and cerebellum, while no changes were found in medial and lateral pallia.

$\mathrm{iHg}$ has a great affinity for selenium in the brain, being mainly accumulated as mercuric selenide (HgSe) (Korbas et al., 2010). This complex was described as a non-toxic and inert form for the cellular components (Korbas et al., 2010), but changes on biochemical endpoints in fish were described after exposure to $\mathrm{HgCl}_{2}$ (Berntssen et al., 2003), as well as impairment of swimming behavior (Vieira et al., 2009). This pointed out the indirect effects of $\mathrm{HgCl}_{2}$ in fish brain probably related with $\mathrm{Hg}$ complexation with $\mathrm{Se}$, namely by its interference with cellular components that depend on this essential element (e.g., Se-dependent enzymes). In fact, in the current experiment another set of $D$. sargus brain was analyzed for antioxidant enzymes, being glutathione peroxidase consistently inhibited during exposure to $\mathrm{iHg}$ (Albuquerque et al., unpublished data). It is also plausible that $\mathrm{iHg}$ exposure of $D$. sargus resulted in an accumulation of $\mathrm{HgS}$ complex in brain cells, similarly to observations in fish liver and kidney (Baatrup and Danscher, 1987). HgS is mainly stored in lysosomes probably preventing biological effects, although long-term effects of HgS would be expected depending on $\mathrm{HgS}$ interference with lysosomal enzymes (Møller-Madsen and Danscher, 1986). In fact, the subcellular distribution of $\mathrm{Hg}$ is considered essential to predict Hg toxicity (Le Faucheur et al., 2014). For instance, in algae, organelles and heat denatured proteins represent the Hg-sensitive fractions, while granules and heat-stable proteins are involved in cellular protection against $\mathrm{Hg}$ (Le Faucheur et al., 2014). Overall, to interpret more accurately morphometric changes in the brain of $D$. sargus upon iHg exposure, it would be important to know intracellular speciation of $\mathrm{Hg}$, as well as its subcellular distribution. While it is known that $\mathrm{iHg}$ can form complexes with Se or S in brain of rodents, allowing some extrapolation for fish, no information is available on $\mathrm{iHg}$ subcellular distribution in fish brain.

Only a few studies have focused in the neurotoxicity of $\mathrm{Hg}$ in fish (Berntssen et al., 2003), but there are a number of works carried out in rodents on this thematic, all emphasizing that the mechanisms of $\mathrm{Hg}$ toxicity in brain have not been fully elucidated yet. Apoptosis is possibly one of the mechanisms behind $\mathrm{Hg}$ toxicity (Toimela and Tähti, 2004), leading to a reduction in the number of brain cells. In fact, apoptosis is a highly conserved cell death process involved in tissue remodeling and degeneration in a variety of cell types (Ceccatelli et al., 2010). Previous studies reported that $\mathrm{Hg}$ (mainly $\mathrm{MeHg}$ ) causes apoptosis in several model organisms, namely in rat cerebellum (Nagashima et al., 1995; Nagashima, 1997) and mice cortex (Fujimura et al., 2009). Cell death via apoptosis may also be involved in the loss of astrocytes reported in the brain of monkeys 
exposed chronically to low levels of $\mathrm{MeHg}$ (Charleston et al., 1995). Moreover, fish brain showed a diffuse necrosis after 4 months of exposure to $\mathrm{iHg}$ (Berntssen et al., 2003). The current loss of brain cells in hypothalamus, optic tectum and cerebellum can be an evidence of apoptosis induced by $\mathrm{iHg}$ accumulation and future studies should evaluate this hypothesis. Marginally, higher pro-oxidant levels can cause cell death by overstimulation of physiological signaling or by recruitment of cytotoxic reactions (Dypbukt et al., 1994). Interestingly, in a parallel study the activities of antioxidant enzymes in brain of white seabream exposed to $\mathrm{iHg}$ for 7 days, pointed out the overproduction of reactive oxygen species (Albuquerque et al., unpublished data); this concomitant effect supports the previous hypothesis. Moreover, oxidative damage in brain at E7 was hinted by the enhancement of protein carbonyl groups, highlighting the vulnerability of this organ to iHg deposition (Albuquerque et al., unpublished data). The loss of brain cells recorded in cerebellum after 7 days of $\mathrm{Hg}$ deposition was accompanied by a decrease of volume in this area.

Cell proliferation in brain of teleost fish occurs throughout life (Maruska et al., 2012). For instance, within a period of $2 \mathrm{~h}$, approximately 100,000 cells (corresponding to roughly $0.2 \%$ of the total population of brain cells) enter the $S$-phase of mitosis in the species Apteronotus leptorhynchus (Zupanc and Ott, 1999). Hence, the lower number of cells observed in several brain regions of $D$. sargus after exposure to $\mathrm{iHg}$ may also be related with the inhibition of cell proliferation, as observed in the hippocampus and cerebellum of rat exposed to $\mathrm{MeHg}$ (Burke et al., 2006). So far, it remains unknown if $\mathrm{iHg}$ can reduce cell proliferation in fish brain. Nevertheless, cerebellar mechanical lesions in fish can induce high proliferative activity especially in areas in close vicinity to the injury, although the number of cells produced also increased in other regions (Zupanc and Ott, 1999). Keeping these findings in view, it should also be hypothesized that the loss of brain cells in hypothalamus, optic tectum and cerebellum of $D$. sargus was not fully compensated by cell proliferation.

Brain morphometric evaluation at E14 revealed a recovery of hypothalamus, and cerebellum, since an identical number of brain cells and a similar volume of cerebellum were found in exposed and control fish. This morphometric recovery was found together with an elevated deposition of $\mathrm{iHg}$ in brain, suggesting that some adaptive mechanisms were probably activated between E7 and E14. Several phenomena can be on the basis of brain cells adaptation to increasingly levels of $\mathrm{iHg}$ accumulation, being the activation of antioxidant systems one the most plausible mechanisms. In fact, an activation of antioxidant enzymes (superoxide dismutase-SOD and glutathione peroxidase-GPx) was found in the brain of white seabream at E14 (Albuquerque et al., unpublished data), corroborating their involvement in cellular adaptation to iHg. Moreover, the induction of SOD and GPX at E14 seemed to prevent oxidative damage, contrarily to what occurred at E7 as discussed above. Recovery of hypothalamus and cerebellum implies the formation of new brain cells at E14. Teleost fish brain possesses an enormous potential for regeneration that would involve different processes, namely: (i) elimination of damaged cells by apoptosis, instead of necrosis; (ii) increased production of new neurons that replace neurons lost by injury; and (iii) activation of developmental mechanisms that mediate directed migration of the new cells to the site of injury, the differentiation of the young cells, and their integration into the existing neural network (Zupanc, 2009). Future studies should elucidate on the appropriate mechanism(s) involved in the recovery of hypothalamus and cerebellum of fish.

The higher accumulation of $\mathrm{iHg}$ in brain (at E14) was not followed by increased cells loss, which is apparently an incongruent result. However, it is in agreement with a non-monotonic dose-response model, typically characterized by the occurrence of opposite effects at low and high doses. Non-monotonic responses were previously identified for a large number of chemicals and physical agents, including metals (Calabrese and Blain, 2011).

The toxicodynamics of $\mathrm{iHg}$ in the optic tectum was distinct from that of the hypothalamus and cerebellum, as disclosed by morphometric results after E14 and 28 days of post-exposure. No changes in the number of brain cells were found at PE28 in the hypothalamus and cerebellum, probably meaning that the adaptive mechanisms previously invoked at E14 were maintained in both brain regions. This recovery was not followed by an elimination of iHg considering bioaccumulation data for the whole brain published in Pereira et al. (2015). Based on that slow elimination of iHg from the brain it is improbable that an area-specific elimination of $\mathrm{iHg}$ had occurred, corroborating again the hypothesis of adaptation invoked for E14 results. On the contrary, a cell deficit was found in the optic tectum at E14 and PE28, pointing out a higher vulnerability of this area to iHg. This distinct profile suggests that the hypothalamus and cerebellum were only transiently affected by iHg exposure, while optic tectum seems to be more susceptible to iHg deposition.

Overall, the response of the fish brain to $\mathrm{iHg}$ exposure displayed a multiphasic pattern that is complex to interpret. It comprised an initial phase of cells loss in the hypothalamus, cerebellum and optic tectum at E7, as well as a contraction of the cerebellum molecular layer volume due to iHg deposition. Then, a phase of homeostatic adjustments occurred at higher levels of $\mathrm{iHg}$ (E14) in the hypothalamus and cerebellum, leading to brain recovery as expressed by an identical number of cells in the two brain regions in both exposed and control animals. On the other hand, in the optic tectum the elevated accumulation of $\mathrm{iHg}$ that was maintained in brain led to morphometric effects along all times analyzed (E7, E14 and PE28).

Finally, it is also plausible that mercury exposure can result in abnormal connectivity between the brain regions. For instance, $\mathrm{Hg}$ is able to induce axonal degeneration (Fujimura and Usuki, 2012), and change neuronal excitability, which eventually lead to degradation of the network connectivity (Xu et al., 2012). However, to the best of our knowledge, the putative changes in long-distance neuronal connections due to $\mathrm{Hg}$ exposure, in both mammals and fish brains, have not been addressed so far.

\subsection{Swimming behavior impairment and association with brain morphological alterations}

The impairments of swimming performance found in the current study cannot be explained by decreased fish condition index, since $K$ values did not vary significantly between control and exposed fish at any experimental time.

The loss of brain cells in the optic tectum and cerebellum (molecular layer) after 7 days of exposure to $\mathrm{iHg}$ might influence the schooling, sensory and motor function of $D$. sargus. In fact, the optic tectum plays a significant role in correlating optic and exteroceptive impulses (Roy et al., 2006), while the cerebellum is essential for the classical conditioning of simple motor reflexes, emotional learning and spatial cognition (Rodriguez et al., 2005). D. sargus displayed impairment of motor function at least at the strength level after 7 days of exposure to $\mathrm{iHg}$, as evidenced by the smaller distance swam in the first run in comparison with control fish, as well as the corresponding lower velocity. Those impairments can be related with damage of optic tectum and cerebellum after iHg deposition. Vieira et al. (2009) also observed a reduction of fish swimming resistance and covered distance after iHg exposure, although morphological alterations in brain were not evaluated. It should be noted however, that gross motor alterations do not seem to be present, as the total distance swam, total time swam, and swimming frequency during the 3 min' testing were similar between $\mathrm{E} 7$ and control groups.

In fish, as in mammalians, anxiety is the response to potential or distant threat (Maximino et al., 2012). This seems to be the case of 
the exploitation-based model of the present work, where the fish were placed in the extreme of a $4 \mathrm{~m}$ tube. Importantly, the water height inside the tube does not allow an evaluation of diving, a reported measure of anxiety in the novel tank diving test (Levin et al., 2007), as the fish has just a few centimeters of water above its height in the tube. However, the aversiveness for light areas versus seeking of dark areas is known in fish and mammals based on the dual conflict between the motivation to explore a new environment and neophobia (tendency to avoid a new situation) (Sousa et al., 2006; Maximino et al., 2007, 2012). Thus, the time for refuge in the dark area of the tube may be used as an indirect measure of anxietylike behavior of $D$. sargus. On the other hand, two other behavioral measures were performed, the latency to be dragged and latency to immobility. A shorter latency to be dragged and immobility may represent a decrease in motivation to swim in order to attempt to escape from the BED, therefore a measure of fish helplessness. Since helplessness is a component of depressive-like behavior in rodents (Sousa et al., 2006) we suggest that these two endpoints can be considered an indication of alteration in mood/depressive-like behavior. In addition, since the white seabream apparently develops an aggressive behavior against its conspecifics (Caballero and Castro-Hdez, 2003; Papoutsoglou et al., 2006; Karakatsouli et al., 2007), it is probable that at least the "first run distance", "first run time" and "first run velocity" represent indeed more pure motor behaviors in contrast with later behaviors like "refuge latency", "immobility latency" and "dragging latency" that may represent mood-related traits.

The accumulation of $\mathrm{iHg}$ can result in mood (anxiety/depression) or emotional alterations in humans (Siblerud et al., 1994; Bernhoft, 2012). Here, iHg deposition in brain could result on increased anxiety-like responses in fish associated with the stress of exploiting a new environment; this is pointed out by the lower time that fish spent in the light area of the tube after 7 days of exposure to $\mathrm{iHg}$, in comparison with control fish, corresponding to a lower time to seek refuge in the dark safety area. This behavioral alteration could be the ultimate manifestation of iHg effects in the hypothalamus, since a decline of brain cells was recorded in this area. In fact, the hypothalamus is involved in hormone secretion and homeostasis (Lin et al., 2000), being essential for autonomic and neuroendocrine responses to stress in mammals (Herman and Cullinan, 1997). Curiously, neuropathies in the rat induce decreased volume of the frontal cortex, which were coincident with the onset of altered anxious behavior (Seminowicz et al., 2009). The same association between altered brain volume and onset of mood alterations seemed to occur in the present study. Moreover, a similar rationale may be at the basis of the recovery of $\operatorname{mood} /$ anxiety-like alterations at E14, since they are also paralleled by a recovery in the cerebellum volume that was altered at E7. It is possible that the alterations in cell numbers observed at PE28, although not associated with altered volumes might be responsible per se for the behavioral changes in mood/anxiety.

At the end of the post-exposure time that lasted 28 days (PE28), several behavioral traits seemed to be compromised. At the motor level, previously exposed fish swam a smaller distance and for less time than controls in the first run, and also swam a smaller total distance and a lower number of times than controls during the $3 \mathrm{~min}$ of observation. On the other hand, at the mood/anxiety level, PE28 exposed fish showed a lower immobility latency, which may represent a decreased motivation to swim and seek safety. In support of this hypothesis, exposed fish were also dragged earlier than controls at the end of the testing period (PE28), which may indicate a decreased motivation to escape than control fish. As observed after 7 days of exposure to $\mathrm{iHg}$ and also at the end of the post-exposure time, motor function seemed to be partly compromised and mood/anxiety alterations were found. At the same time, the optic tectum of exposed fish displayed a lower number of brain cells than controls, highlighting the critical role of this area on modulating fish behavior. Moreover, it can be suggested that morphometric alterations in this specific brain area can determine behavioral shifts, even if the cerebellum and hypothalamus remain unaffected.

\section{Conclusions}

According to the present results, it can be concluded that:

- iHg elicited cellular loss (neurons plus glial cells) in specific brain regions of fish, namely in hypothalamus, optic tectum and molecular layer of the cerebellum after 7 days of exposure. Such brain damage was accompanied by impairment of motor function and altered mood/anxiety-like behavior in fish.

- A recovery of the hypothalamus and cerebellum was observed after 14 days of exposure to $\mathrm{iHg}$, probably related with the activation of adaptive mechanisms. The optic tectum showed a higher vulnerability than the hypothalamus and cerebellum, since a cell loss was recorded after longer exposure and also at the end of post-exposure period. At this time, fish expressed also a multitude of behavioral traits, related both with motor function and mood/anxiety status.

- Overall, iHg is a relevant neurotoxicant in fish and inductor of behavioral changes at the motor and mood/anxiety level. This needs to be considered in future studies addressing $\mathrm{Hg}$ toxicity in fish, namely regarding environmental health assessment. Keeping in view the multiphasic response profile of morphometric alterations in brain and associated motor and mood/anxiety behavioral changes, the implementation of several sampling times is strongly recommended under real field situations of hazard evaluation.

\section{Acknowledgements}

Patrícia Pereira (SFRH/BPD/69563/2010) and Joana Raimundo (SFRH/BPD/91498/2012) benefit from a Post-doctoral grant supported by "Fundação para a Ciência e a Tecnologia" (FCT). This work has been supported by the Research project financed by FCT PTDC/AAG-REC/2488/2012 (NEUTOXMER - Neurotoxicity of mercury in fish and association with morphofunctional brain alterations and behavior shifts), as well as by the Centre for Environmental and Marine Studies (CESAM). Sónia Puga and Vera Cardoso benefited from a research grant from NEUTOXMER project (FCT PTDC/AAG-REC/2488/2012). Helpful comments provided by two anonymous reviewers were appreciated. Authors are also grateful to Olinda Araújo for her support to the laboratory work.

\section{References}

Abecasis, D., Bentes, L., Lino, P.G., Santos, M.N., Erzini, K., 2013. Residency, movements and habitat use of adult white seabream (Diplodus sargus) between natural and artificial reefs. Estuar. Coas. Shelf Sci. 118, 80-85.

Allen, J.W., Shanker, G., Tan, K.H., Aschner, M., 2002. The consequences of methylmercury exposure on interactive functions between astrocytes and neurons. Neurotoxicology 23, 755-759.

Almeida, J.R., Oliveira, C., Gravato, C., Guilhermino, L., 2010. Linking behavioural alterations with biomarkers responses in the European seabass Dicentrarchus labrax L. exposed to the organophosphate pesticide fenitrothion. Ecotoxicology 19, 1369-1381

Aschner, M., Ceccatelli, S., 2010. Are neuropathological conditions relevant to ethylmercury exposure? Neurotox. Res. 18, 59-68.

Aschner, M., Farina, M., Rocha, J.T., 2013. Mercury neurotoxicity. In: Kretsinger, R., Uversky, V., Permyakov, E. (Eds.), Encyclopedia of Metalloproteins. Springer, New York, pp. 1362-1367.

ATSDR (1999). Toxicological profile for mercury. Agency for Toxic Substances and Disease Registry. Washington DC. (http://www.atsdr.cdc.gov/toxprofiles/tp. asp?id=115\&tid=24). 
Baatrup, E., Danscher, G., 1987. Cytochemical demonstration of mercury deposits in trout liver and kidney following methyl mercury intoxication: differentiation of two mercury pools by selenium. Ecotoxicol. Environ. Saf. 14, 129-141.

Bernhoft, R.A., 2012. Mercury toxicity and treatment: a review of the literature. J. Environ. Public Health 2012, 460508

Berntssen, M.H.G., Aatland, A., Handy, R.D., 2003. Chronic dietary mercury exposure causes oxidative stress, brain lesions, and altered behaviour in Atlantic salmon (Salmo salar) parr. Aquat. Toxicol. 65, 55-72.

Burke, K., Cheng, Y., Li, B., Petrov, A., Joshi, P., Berman, R., Reuhl, K.R., DiCicco-Bloom, E., 2006. Methylmercury elicits rapid inhibition of cell proliferation in the developing brain and decreases cell cycle regulator, cyclin E. Neurotoxicology 27, 970-981.

Caballero, C., Castro-Hdez, J.J., 2003. Effect of competitor density on the aggressiveness of juvenile white seabream (Diplodus sargus cadenati de la Paz, Bauchot and Daget, 1974). Aggress. Behav. 29, 279-284.

Ceccatelli, S., Daré, E., Moors, M., 2010. Methylmercury-induced neurotoxicity and apoptosis. Chem.-Biol. Interact. 188, 301-308.

Charleston, J.S., Body, R.L., Bolender, R.P., Mottet, N.K., Vahter, M.E., Burbacher, T.M., 1995. Changes in the number of astrocytes and microglia in the thalamus of the monkey Macaca fascicularis following long-term subclinical methylmercury exposure. Neurotoxicology 17, 127-138.

Charleston, J.S., Bolender, R.P., Mottet, N.K., Body, R.L., Vahter, M.E., Burbacher, T.M., 1994. Increases in the number of reactive glia in the visual cortex of Macaca fascicularis following subclinical long-term methyl mercury exposure. Toxicol. Appl. Pharmacol. 129, 196-206.

Calabrese, E.J., Blain, R.B., 2011. The hormesis database: the occurrence of hormeticdose responses in the toxicological literature. Regul. Toxicol. Pharmacol. 61, 73-81.

De Flora, S., Bennicelli, C., Bagnasco, M., 1994. Genotoxicity of mercury compounds. A review. Mutat. Res./Rev. Genet. Toxicol. 317, 57-79.

Dypbukt, J.M., Ankarcrona, M., Burkitt, M., Sjöholm, Å., Ström, K., Orrenius, S., Nicotera, P., 1994. Different prooxidant levels stimulate growth, trigger apoptosis, or produce necrosis of insulin-secreting RINm5F cells. The role of intracellular polyamines. J. Biol. Chem. 269, 30553-30560.

EPA(2015). Basic Information about Mercury in Drinking Water. Basic Information about Regulated Drinking Water Contaminants. US EPA. [online] Available at: http://water.epa.gov/drink/contaminants/basicinformation/mercury.cfm (accessed 23.11.2015.)

Eto, K., 1997. Review article: pathology of minamata disease. Toxicol. Pathol. 25, 614-623

Farina, M., Avila, D.S., da Rocha, J.B.T., Aschner, M., 2013. Metals, oxidative stress and neurodegeneration: a focus on iron, manganese and mercury. Neurochem. Int. 62, 575-594

Figueiredo, M., Morato, T., Barreiros, J.P., Afonso, P., Santos, R.S., 2005. Feeding ecology of the white seabream, Diplodus sargus, and the ballan wrasse, Labrus bergylta, in the Azores. Fish. Res. 75, 107-119.

Fujimura, M., Usuki, F., 2012. Differing effects of toxicants (methylmercury, inorganic mercury, lead, amyloid $\beta$, and rotenone) on cultured rat cerebrocortical neurons: differential expression of Rho proteins associated with neurotoxicity. Toxicol. Sci. 126, 506-514

Fujimura, M., Usuki, F., Sawada, M., Takashima, A., 2009. Methylmercury induces neuropathological changes with tau hyperphosphorylation mainly through the activation of the c-jun-N-terminal kinase pathway in the cerebral cortex, but not in the hippocampus of the mouse brain. Neurotoxicology 30, 1000-1007.

Gilderhus, P.A., Marking, L.L., 1987. Comparative efficacy of 16 anesthetic chemicals on rainbow trout. N. Am. J. Fish. Manage. 7, 288-292.

Gravato, C., Guilhermino, L., 2009. Effects of benzo(a) pyrene on seabass (Dicentrarchus labrax L.): biomarkers, growth and behavior. Hum. Ecol. Risk Asses. Int. J. 15, 121-137.

Gundersen, H., Bendtsen, T.F., Korbo, L. Marcussen, N., Møller, A., Nielsen, K. Nyengaard, J., Pakkenberg, B., Sørensen, F.B., Vesterby, A., 1988. Some new, simple and efficient stereological methods and their use in pathological research and diagnosis. APMIS 96, 379-394.

Gundersen, H., Jensen, E., 1987. The efficiency of systematic sampling in stereology and its prediction. J. Microsc. 147, 229-263.

Herman, J.P., Cullinan, W.E., 1997. Neurocircuitry of stress: central control of the hypothalamo-pituitary-adrenocortical axis. Trends Neurosci. 20, 78-84.

Hernández-Moreno, D., Pérez-López, M., Soler, F., Gravato, C., Guilhermino, L. 2011. Effects of carbofuran on the sea bass (Dicentrarchus labrax L.): study of biomarkers and behaviour alterations. Ecotoxicol. Environ. Saf. 74, 1905-1912.

Horvat, M., Nolde, N., Fajon, V., Jereb, V., Logar, M., Lojen, S., Jacimovic, R., Falnoga, I., Liya, Q., Faganeli, J., Drobne, D., 2003. Total mercury, methylmercury and selenium in mercury polluted areas in the province Guizhou, China. Sci. Total Environ. 304, 231-256.

Hou, J., Riise, J., Pakkenberg, B., 2012. Application of immunohistochemistry in stereology for quantitative assessment of neural cell populations illustrated in the Göttingen minipig. PLoS One 7, e43556-e43556.

Ikenaga, T., 2013. Teleost fish. In: Manto, M., Schmahmann, J., Rossi, F., Gruol, D. Koibuchi, N. (Eds.), Handbook of the Cerebellum and Cerebellar Disorders. Springer, Netherlands, pp. 1463-1480.

Karakatsouli, N., Papoutsoglou, S.E., Manolessos, G., 2007. Combined effects of rearing density and tank colour on the growth and welfare of juvenile white sea bream Diplodus sargus L. in a recirculating water system. Aquacult. Res. 38 1152-1160.

Kaslin, J., Brand, M., 2013. Cerebellar development and neurogenesis in zebrafish. In: Manto, M., Schmahmann, J., Rossi, F., Gruol, D., Koibuchi, N. (Eds.),
Handbook of the Cerebellum and Cerebellar Disorders. Springer, Netherlands, pp. 1441-1462.

Keuker, J.I.H., Vollmann-Honsdorf, G.K., Fuchs, E., 2001. How to use the optical fractionator: an example based on the estimation of neurons in the hippocampal CA1 and CA3 regions of tree shrews. Brain Res. Protoc. 7, 211-221.

Korbas, M., Lai, B., Vogt, S., Gleber, S.-C., Karunakaran, C., Pickering, I.J., Krone, P.H., George, G.N., 2013. Methylmercury targets photoreceptor outer segments. ACS Chem. Biol. 8, 2256-2263.

Korbas, M., MacDonald, T.C., Pickering, I.J., George, G.N., Krone, P.H., 2011. Chemical form matters: differential accumulation of mercury following inorganic and organic mercury exposures in zebrafish larvae. ACS Chem. Biol. 7, 411-420.

Korbas, M., O’Donoghue, J.L., Watson, G.E., Pickering, I.J., Singh, S.P., Myers, G.J., Clarkson, T.W., George, G.N., 2010. The chemical nature of mercury in human brain following poisoning or environmental exposure. ACS Chem. Neurosci. 1 $810-818$.

Levin, E.D., Bencan, Z., Cerutti, D.T., 2007. Anxiolytic effects of nicotine in zebrafish. Physiol. Behav. 90, 54-58.

Le Faucheur, S., Campbell, P.G.C., Fortin, C., Slaveykova, V.I., 2014. Interactions between mercury and phytoplankton: speciation, bioavailability, and internal handling. Environ. Toxicol. Chem. 33, 1211-1224.

Li, P., Feng, X.B., Qiu, G.L., Shang, L.H., Li, Z.G., 2009. Mercury pollution in Asia: a review of the contaminated sites. J. Hazard. Mater. 168, 591-601.

Lin, X., Volkoff, H., Narnaware, Y., Bernier, N.J., Peyon, P., Peter, R.E., 2000. Brain regulation of feeding behavior and food intake in fish. Comp. Biochem. Physiol. Part A: Mol. Integr. Physiol. 126, 415-434.

Little, E.E., Finger, S.E., 1990. Swimming behavior as an indicator of sublethal toxicity in fish. Environ. Toxicol. Chem. 9, 13-19.

Liu, S., 2013. Stellate cells: synaptic processing and plasticity. In: Manto, M. Schmahmann, J., Rossi, F., Gruol, D., Koibuchi, N. (Eds.), Handbook of the Cerebellum and Cerebellar Disorders. Springer, Netherlands, pp. 809-828.

Maruska, K.P., Carpenter, R.E., Fernald, R.D., 2012. Characterization of cell proliferation throughout the brain of the African cichlid fish Astatotilapia burtoni and its regulation by social status. J. Comp. Neurol. 520, 3471-3491.

Maximino, C., Benzecry, R., Oliveira, K.R.M., Batista d, E.J.O., Herculano, A.M., Rosemberg, D.B., de Oliveira, D.L., Blaser, R., 2012. A comparison of the light/dark and novel tank tests in zebrafish. Behaviour 149, 1099-1123.

Maximino, C., Marques de Brito, T., Dias, C.A.G.d.M., Gouveia, A., Morato, S., 2010. Scototaxis as anxiety-like behavior in fish. Nat. Protoc. 5, 209-216.

Maximino, C., Marques, T., Dias, F., Cortes, F.V., Taccolini, I.B., Pereira, P.M., Colmanetti, R., Gazolla, R.A., Tavares, R.I., Rodrigues, S.T.K., 2007. A comparative analysis of the preference for dark environments in five teleosts. Int. J. Comp. Psychol. 20, 351-367.

Mello-Carpes, P.B., Barros, W., Borges, S., Alves, N., Rizzetti, D., Peçanha, F.M., Vassallo, D.V., Wiggers, G.A., Izquierdo, I., 2013. Chronic exposure to low mercury chloride concentration induces object recognition and aversive memories deficits in rats. Int. J. Dev. Neurosci. 31, 468-472.

Mieiro, C., Pereira, M., Duarte, A., Pacheco, M., 2011. Brain as a critical target of mercury in environmentally exposed fish (Dicentrarchus labrax)-bioaccumulation and oxidative stress profiles. Aquat. Toxicol. 103, 233-240.

Mieiro, C.L., Ahmad, I., Pereira, M.E., Duarte, A.C., Pacheco, M., 2010. Antioxidant system breakdown in brain of feral golden grey mullet (Liza aurata) as an effect of mercury exposure. Ecotoxicology 19, 1034-1045.

Møller-Madsen, B., Danscher, G., 1986. Localization of mercury in CNS of the rat. Environ. Res. 41, 29-43.

Møller-Madsen, B., Danscher, G., 1991. Localization of mercury in CNS of the rat: IV. The effect of selenium on orally administered organic and inorganic mercury. Toxicol. Appl. Pharmacol. 108, 457-473.

Monnet-Tschudi, F., Zurich, M.-G., Honegger, P., 1996. Comparison of the developmental effects of two mercury compounds on glial cells and neurons in aggregate cultures of rat telencephalon. Brain Res. 741, 52-59.

Moraes-Silva, L., Siqueira, L.F., Oliveira, V.A., Oliveira, C.S., Ineu, R.P., Pedroso, T.F., Fonseca, M.M., Pereira, M.E., 2014. Preventive effect of $\mathrm{CuCl}_{2}$ on behavioral alterations and mercury accumulation in central nervous system induced by $\mathrm{HgCl}_{2}$ in newborn rats. J. Biochem. Mol. Toxicol. 28, 328-335.

Muñoz-Cueto, J.A., 2001. An atlas of the brain of the gilthead seabream (Sparus aurata). In: Center of Marine Biotechnology. Maryland Sea Grant College, Baltimore.

Nagashima, K., 1997. A review of experimental methylmercury toxicity in rats: neuropathology and evidence for apoptosis. Toxicol. Pathol. 25, 624-631.

Nagashima, K., Fujii, Y., Tsukamoto, T., Nukuzuma, S., Satoh, M., Fujita, M., Fujioka, Y., Akagi, H., 1995. Apoptotic process of cerebellar degeneration in experimental methylmercury intoxication of rats. Acta Neuropathol. 91, 72-77.

Nielsen, R.D., Abitz, M., Pakkenberg, B., 2011. Neuron and glial cell numbers in the mediodorsal thalamic nucleus in brains of schizophrenic subjects. Image Anal. Stereol. 27, 133-141.

Ohgoh, M., Shimizu, H., Ogura, H., Nishizawa, Y., 2000. Astroglial trophic support and neuronal cell death. J. Neurochem. 75, 925-933.

Papoutsoglou, S.E., Karakatsouli, N., Pizzonia, G., Dalla, C., Polissidis, A., Papadopoulou-Daifoti, Z., 2006. Effects of rearing density on growth, brain neurotransmitters and liver fatty acid composition of juvenile white sea bream Diplodus sargus L. Aquacult. Res. 37, 87-95.

Pereira, M.E., Lillebø, A.I., Pato, P., Válega, M., Coelho, J.P., Lopes, C.B., Rodrigues, S. Cachada, A., Otero, M., Pardal, M.A., Duarte, A.C., 2009. Mercury pollution in Ria 
de Aveiro (Portugal): a review of the system assessment. Environ. Monit. Assess. 155, 39-49.

Pereira, P., Raimundo, J., Barata, M., Araujo, O., Pousao-Ferreira, P., Canario, J., Almeida, A., Pacheco, M., 2015. A new page on the road book of inorganic mercury in fish body-tissue distribution and elimination following waterborne exposure and post-exposure periods. Metallomics 7, 525-535.

Rodriguez, F., Duran, E., Gomez, A., Ocana, F., Alvarez, E., Jimenez-Moya, F., Broglio, C., Salas, C., 2005. Cognitive and emotional functions of the teleost fish cerebellum. Brain Res. Bull. 66, 365-370.

Rouleau, C., Borg-Neczak, K., Gottofrey, J., Tjälve, H., 1999. Accumulation of waterborne mercury (II) in specific areas of fish brain. Environ. Sci. Technol. 33, 3384-3389.

Roy, S., Chattoraj, A., Bhattacharya, S., 2006. Arsenic-induced changes in optic tectal histoarchitecture and acetylcholinesterase - acetylcholine profile in Channa punctatus: amelioration by selenium. Comp. Biochem. Physiol. Part C: Toxicol. Pharmacol. 144, 16-24.

Seminowicz, D.A., Laferriere, A.L., Millecamps, M., Yu, J.S., Coderre, T.J., Bushnell, M.C., 2009. MRI structural brain changes associated with sensory and emotional function in a rat model of long-term neuropathic pain. Neuroimage 47 (3), 1007-1014

Scott, G.R., Sloman, K.A., 2004. The effects of environmental pollutants on complex fish behaviour: integrating behavioural and physiological indicators of toxicity. Aquat. Toxicol. 68, 369-392.

Siblerud, R.L., Motl, J., Kienholz, E., 1994. Psychometric evidence that mercury from silver dental fillings may be an etiological factor in depression, excessive anger, and anxiety. Psychol. Rep. 74, 67-80.

Slattery, D.A., Cryan, J.F., 2012. Using the rat forced swim test to assess antidepressant-like activity in rodents. Nat. Protoc. 7, 1009-1014.

Sørensen, F.W., Larsen, J.O., Eide, R., Schiønning, J.D., 2000. Neuron loss in cerebellar cortex of rats exposed to mercury vapor: a stereological study. Acta Neuropathol. 100, 95-100.

Sousa, N., Almeida, O.F.X., Wotjak, C.T., 2006. A hitchhiker's guide to behavioral analysis in laboratory rodents. Genes, Brain Behav. 5, 5-24.

Toimela, T., Tähti, H., 2004. Mitochondrial viability and apoptosis induced by aluminum, mercuric mercury and methylmercury in cell lines of neural origin. Arch. Toxicol. 78, 565-574

Vahter, M.E., Mottet, N.K., Friberg, L.T., Lind, S.B., Charleston, J.S., Burbacher, T.M., 1995. Demethylation of methyl mercury in different brain sites of Macaca fascicularis monkeys during long-term subclinical methyl mercury exposure. Toxicol. Appl. Pharmacol. 134, 273-284.

Vieira, L.R., Gravato, C., Soares, A.M.V.M., Morgado, F., Guilhermino, L., 2009. Acute effects of copper and mercury on the estuarine fish Pomatoschistus microps: linking biomarkers to behaviour. Chemosphere 76, 1416-1427.
Wang, M., Wang, Y., Wang, J., Lin, L., Hong, H., Wang, D., 2011. Proteome profiles in medaka (Oryzias melastigma) liver and brain experimentally exposed to acute inorganic mercury. Aquat. Toxicol. 103, 129-139.

Wang, Y., Wang, D., Lin, L., Wang, M., 2015. Quantitative proteomic analysis reveals proteins involved in the neurotoxicity of marine medaka Oryzias melastigma chronically exposed to inorganic mercury. Chemosphere 119, 1126-1133.

Watras, C.J., Back, R.C., Halvorsen, S., Hudson, R.J.M., Morrison, K.A., Wente, S.P., 1998. Bioaccumulation of mercury in pelagic freshwater food webs. Sci. Total Environ. 219, 183-208.

West, M., Slomianka, L., Gundersen, H.J.G., 1991. Unbiased stereological estimation of the total number of neurons in the subdivisions of the rat hippocampus using the optical fractionator. Anat. Rec. 231, 482-497.

West, M.J., 2012. Systematic versus random sampling in stereological studies. Cold Spring Harbor Protocols 2012, pdb. top071837.

West, M.J., 2013a. Getting started in stereology. Cold Spring Harbor Protocols 2013, pdb. top071845.

West, M.J., 2013b. Optimizing the sampling scheme for a stereological study: how many individuals, sections, and probes should be used. Cold Spring Harbor Protocols 2013, pdb. top071852.

Wojcik, D.P., Godfrey, M.E., Christie, D., Haley, B.E., 2006. Mercury toxicity presenting as chronic fatigue, memory impairment and depression: diagnosis, treatment, susceptibility, and outcomes in a New Zealand general practice setting (1994-2006). Neuroendocrinol. Lett. 27, 415-423.

Xu, F., Farkas, S., Kortbeek, S., Zhang, F.-X., Chen, L., Zamponi, G.W., Syed, N.I., 2012. Mercury-induced toxicity of rat cortical neurons is mediated through N-methyl-D-Aspartate receptors. Mol. Brain 5, 1-14.

Zheng, W., Aschner, M., Ghersi-Egea, J.-F., 2003. Brain barrier systems: a new frontier in metal neurotoxicological research. Toxicol. Appl. Pharmacol. 192, $1-11$.

Zupanc, G.K.H., 2008. Adult neurogenesis and neuronal regeneration in the brain of teleost fish. J. Physiol.-Paris 102, 357-373.

Zupanc, G.K.H., 2009. Towards brain repair: insights from teleost fish. Semin. Cell Dev. Biol. 20, 683-690.

Zupanc, G.K.H., Ott, R., 1999. Cell proliferation after lesions in the cerebellum of adult teleost fish: time course, origin, and type of new cells produced. Exp. Neurol. 160, 78-87.

Zupanc, G.K.H., Sîrbulescu, R.F., 2013. Teleost fish as a model system to study successful regeneration of the central nervous system. In: Heber-Katz, E. Stocum, D.L. (Eds.), New Perspectives in Regeneration. Springer, Berlin Heidelberg, pp. 193-233. 